\title{
A Prosurvival and Proangiogenic Stem Cell Delivery System to Promote Ischemic Limb
}

\section{Regeneration}

Yanyi $\mathrm{Xu}^{1 *}$, Minghuan $\mathrm{Fu}^{1,2^{*}}$, Zhihong $\mathrm{Li}^{1,3^{*}}$, Zhaobo $\mathrm{Fan}^{1}$, Xiaofei $\mathrm{Li}^{1}$, Ying Liu ${ }^{4}$, Peter M. Anderson ${ }^{1}$, Xiaoyun Xie ${ }^{4}$, Zhenguo Liu ${ }^{5}$, Jianjun Guan ${ }^{1,6}$

1 Department of Materials Science and Engineering, The Ohio State University, Columbus, OH, 43210

2 Department of Gerontology, Sichuan Academy of Medical Sciences \& Sichuan Provincial People's Hospital, Chengdu, Sichuan, 610072, China

3 Division of General Surgery, Shanghai Pudong New District Zhoupu Hospital, Shanghai, 201200, China

4 Department of Gerontology, Tongji Hospital, Tongji University, Shanghai, China

5 Davis Heart and Lung Research Institute, The Ohio State University, OH, 43210

6 Tongji Hospital, Tongji University, Shanghai, China

* These authors contributed equally to this work.

\section{Corresponding Author:}

Jianjun Guan, Ph.D.

Associate Professor

Department of Materials Science and Engineering

The Ohio State University

2041 College Road

Columbus, $\mathrm{OH} 43210$

Phone: 614-292-9743

Email: guan.21@osu.edu 


\begin{abstract}
Stem cell therapy is one of the most promising strategies to restore blood perfusion and promote muscle regeneration in ischemic limbs. Yet its therapeutic efficacy remains low owing to the inferior cell survival under the low oxygen and nutrient environment of the injured limbs. To increase therapeutic efficacy, high rates of both short- and long-term cell survival are essential, which current approaches do not support. In this work, we hypothesized that a high rate of short-term cell survival can be achieved by introducing a prosurvival environment into the stem cell delivery system to enhance cell survival before vascularization is established; and that a high rate of long-term cell survival can be attained by building a proangiogenic environment in the system to quickly vascularize the limbs. The system was based on a biodegradable and thermosensitive poly(N-Isopropylacrylamide)-based hydrogel, a prosurvival and proangiogenic growth factor bFGF, and bone marrow-derived mesenchymal stem cells (MSCs). bFGF can be continuously released from the system for 4 weeks. The released bFGF significantly improved MSC survival and paracrine effects under low nutrient and oxygen conditions $\left(0 \% \mathrm{FBS}\right.$ and $\left.1 \% \mathrm{O}_{2}\right)$ in vitro. The prosurvival effect of the bFGF on MSCs was resulted from activating cell Kruppel-like factor 4 (KLF4) pathway. When transplanted into the ischemic limbs, the system dramatically improved MSC survival. Some of the engrafted cells were differentiated into skeletal muscle and endothelial cells, respectively. The system also promoted the proliferation of host cells. After only 2 weeks of implantation, tissue blood perfusion was completely recovered; and after 4 weeks, the muscle fiber diameter was restored similarly to that of the normal limbs. These pronounced results demonstrate that the developed stem cell delivery system has a potential for ischemic limb regeneration.
\end{abstract}

Keywords: Stem cells; Growth factors; Angiogenesis; Hydrogel; Injectable; Myogenic differentiation; skeletal muscle regeneration 


\section{Introductions}

Atherosclerotic peripheral artery disease (PAD) affects more than 27 million people in North America and Europe.[1, 2] PAD decreases blood perfusion in the tissues and causes tissue ischemia. Critical limb ischemia (CLI) represents the most severe form of PAD. It is characterized by low blood perfusion, severe tissue ischemia, and degenerated skeletal muscle. Quick restoration of blood perfusion to salvage existing cells and promotion of muscle repair represent the optimal goals for CLI treatment.[1, 3-8] However, current surgical procedures show limited efficacy.[1, 8-10]

To improve therapeutic efficacy, approaches like drug delivery [11] and stem cell therapy [3, 12-19] have been explored. The former involves delivery of growth factors that either stimulate vascularization or promote muscle regeneration into the limbs. For example, VEGF, PDGFBB and bFGF have been used for vascularization [20-22], while IGF-1 has been employed for muscle regeneration [23, 24]. Different studies have demonstrated that delivery of two or more types of growth factors with different functions can result in a greater therapeutic efficacy than delivery of single growth factors [11]. Efficacy of the drug delivery approach is dependent on the amount of bioactive drugs released to the ischemic limb, duration of the drug release, and sequence of the release. Overall, current drug delivery approach shows limited success due to the rapid release of delivered drugs, loss of bioactivity, inadequate amount of drug released to the tissue, and inappropriate drug gradients and release sequence [11]. Cell therapy is an alternative approach. It includes direct injection of stem cells into the tissue or encapsulating cells in the constructs followed by injection $[1,15,25]$. The transplanted stem cells serve two purposes: differentiation to replace damaged host cells, and providing paracrine effects for vascularization and muscle repair.

Various stem cell types including embryonic stem cells (ESCs) [26], mesenchymal stem cells (MSCs) 
[14, 15, 25, 27, 28], adipose tissue-derived cells [29-32], cell lines selected based on the presence of specific markers [33, 34], and induced pluripotent stem cells (iPSCs) [16] have been used for ischemic limb regeneration. Among them, MSCs stand out because of their ability to differentiate into myogenic lineages for muscle regeneration, and into endothelial cells for vascularization $[35,36]$. MSCs also provide paracrine effects for ischemic limb regeneration. Among the number of different growth factors they secrete, IGF-1 promotes myoblast proliferation and satellite cell differentiation [37-39], and bFGF, VEGF and PDGFBB stimulate angiogenesis. Therefore, MSCs have the potential to induce not only vascularization, but also muscle repair in the ischemic limb through direct and indirect effects.

Various animal studies have demonstrated that stem cell therapy could, to some extent, improve blood perfusion in the ischemic limb and even promote muscle repair in some cases $[1,40,41]$. However, clinical trials have shown only a transient therapeutic benefit [1, 42]. Overall, current stem cell therapy has a low efficacy in improving blood perfusion and muscle repair.[1, 42] One of the key causes is the poor survival rates of transplanted cells [1, 41-43]. Several studies have demonstrated that only 20\% of cells remained in the tissue $24 \mathrm{~h}$ after transplantation, and only $\sim 3 \%$ remained after 30 days [43-46]. Among the possible triggers for cell death, such as ischemia, immune response, inflammation and oxidative stress, ischemia represents the most significant problem to be solved [1, 41-43].

Promoting high rates of both short- and long-term cell survival under ischemic conditions is one of the key steps to significantly increase therapeutic efficacy of stem cell therapy for CLI [8]. To improve cell survival under ischemia, approaches have been used including blocking the apoptotic signaling pathways of cells $[47,48]$, preconditioning cells before transplantation $[49,50]$, co-transplanting with cells rich in paracrine effects [51, 52], using prosurvival cocktails [53], promoting angiogenesis [51], and co- 
transplanting with hydrogels [54-57]. While these approaches increased cell survival to an extent, achieving high rates of both short- and long-term cell survival remains challenging and insignificantly addressed. Those approaches that induce endogenous cellular survival mechanisms, co-transplant stem cells with other cells, and use prosurvival cocktails, can only temporarily improve cell survival, as adequate vascularization cannot be readily achieved to relieve ischemia for long-term cell survival. The approaches focusing on promoting angiogenesis show significant cell death before angiogenesis can occur. While using hydrogels, such as collagen and hyaluronic acid, can decrease cell apoptosis, vascularization around matrices for long-term cell survival is challenging [54-57].

In this study, we hypothesized that a stem cell delivery system that can continuously release a prosurvival and proangiogenic growth factor will promote both short- and long-term cell survival in the ischemic limbs. The prosurvival effect could promote cell survival before vascularization is established, while the proangiogenic effect could stimulate quick angiogenesis to promote long-term cell survival. Meanwhile, the differentiation of MSCs into endothelial and myogenic lineages, and MSC paracrine effects will enhance vascularization and muscle regeneration. bFGF was used due to its prosurvival and proangiogenic effects $[22,58-63]$. We investigated how the controlled release of bFGF affected MSC survival and paracrine effects in vitro under low nutrient and oxygen conditions, and how the delivery system enhanced MSC survival and differentiation, muscle regeneration and blood perfusion recovery in ischemic limbs.

\section{Experimental Materials and Methods}

\subsection{Materials}

All chemicals were purchased from Sigma-Aldrich unless otherwise stated. 2-hydroxyethyl 
methylmethacrylate (HEMA) was purchased from TCI and passed through an inhibitor remover column to eliminate inhibitor. N-isopropylacrylamide (NIPAAm, Alfa Aesar) was purified by recrystallization for 3 times using hexane. 3,6-Dimethyl-1,4-dioxane-2,5-dione, acryloyl chloride, sodium methoxide and chondroitin sulfate were used as received.

\subsection{Hydrogel synthesis}

The hydrogel was synthesized from NIPAAm, HEMA and a macromer based on acrylic acid and oligolactide (AA-oligoLA). The macromer was synthesized by a two-step method [64]. In the first step, OligoLA was generated by ring-opening polymerization of lactide using $\mathrm{NaOCH}_{3}$ as an initiator. In brief, $50 \mathrm{~g}$ (0.347 mol) of D,L-lactide was dissolved in $100 \mathrm{~mL}$ of $\mathrm{CH}_{2} \mathrm{Cl}_{2}$ and charged into a one-necked flask. One gram $(0.019 \mathrm{~mol})$ of $\mathrm{NaOCH}_{3}$ dissolved in methanol was then added. The reaction was conducted at $0^{\circ} \mathrm{C}$ for $2 \mathrm{~h}$. The mixture was neutralized with $0.1 \mathrm{M} \mathrm{HCl}$, and washed with DI water. The oligoLA was obtained by evaporating the organic layer at $60^{\circ} \mathrm{C}$. Its structure was confirmed by ${ }^{1} \mathrm{H}-\mathrm{NMR}$. The average number of LA units in each oligomer was 2.5. In the second step, oligoLA was esterified using acryloyl chloride. The oligoLA (32.4 g, $151.3 \mathrm{mmol}$ ) was dissolved in $100 \mathrm{~mL}$ of $\mathrm{CH}_{2} \mathrm{Cl}_{2}$. Triethylamine triethylamine $(23.6 \mathrm{~mL}, 169 \mathrm{mmol})$ was then added. After the solution was cooled down to $0^{\circ} \mathrm{C}$ in an ice bath, acryloyl chloride $(13.6 \mathrm{~mL}, 169 \mathrm{~mol})$ was added dropwise for $1 \mathrm{~h}$. The mixture was stirred overnight at room temperature, then rinsed with $0.2 \mathrm{M} \mathrm{Na}_{2} \mathrm{CO}_{3}, 0.1 \mathrm{M} \mathrm{HCl}$ and DI water in sequence. The final product AA-oligoLA was obtained by evaporating the solvent at $40^{\circ} \mathrm{C}$ and purifying using chromatography with ethyl acetate/ $\mathrm{CH}_{2} \mathrm{Cl}_{2}$ as eluent.

Poly(NIPAAm-co-HEMA-co-AA-oligoLA) was synthesized by free radical polymerization following our previous report [65]. In general, stoichiometric amounts of NIPAAm, HEMA and AA-oligoLA (molar ratio 86/10/4) were dissolved in $100 \mathrm{~mL}$ of dioxane in a $250 \mathrm{~mL}$ three-necked flask. The initiator benzoyl 
peroxide was then added. The polymerization was conducted at $60^{\circ} \mathrm{C}$ overnight under. The mixture was precipitated in hexane. The polymer was purified twice using THF/ethyl ether.

The aqueous hydrogel solution had a sol-gel transition temperature (SGTT) of $26.5^{\circ} \mathrm{C}$ as determined by DSC. This allows the hydrogel to solidify at body temperature. The solid hydrogel obtained from the 10 wt $\%$ solution had a breaking strain $>300 \%$ and Young's modulus of $17.1 \pm 3.4 \mathrm{kPa}$ at $37^{\circ} \mathrm{C}$. The final degradation product poly(NIPAM-co-HEMA-co-Acrylic acid) had a SGTT of $41.2^{\circ} \mathrm{C}$. It can thus dissolve in the body fluid.

\subsection{Loading bFGF into the hydrogel, bFGF release kinetics, and bioactivity of the released bFGF}

Hydrogel solution $(10 \%$ w/v) was prepared by dissolving the synthesized hydrogel polymer in Dubucceo's modified phosphate buffer saline (DPBS, $\mathrm{pH}=7.4$ ). The solution was then thoroughly mixed with heparin and bFGF solutions. The final concentrations of heparin and bFGF were $1 \mathrm{mg} / \mathrm{mL}$ and 50 $\mu \mathrm{g} / \mathrm{mL}$, respectively. The function of heparin is to preserve bFGF bioactivity [66]. To measure bFGF release kinetics, $200 \mu \mathrm{L}$ of the mixture was placed in a $2 \mathrm{~mL}$ microcentrifuge tube. The mixture was incubated in a $37^{\circ} \mathrm{C}$ water bath for gelation. The supernatant was then removed and $200 \mu \mathrm{L}$ of release medium, DPBS, was added. The bFGF release study was conducted in the $37^{\circ} \mathrm{C}$ water bath for 4 weeks. At predetermined time points, the release medium was collected and the bFGF concentration was measured using a bFGF ELISA kit (Peprotech) ( $\mathrm{n}=5$ for each condition).

The bioactivity of released bFGF was assessed in terms of its stimulative effect on rat fibroblast proliferation [67]. The cells were seeded into a 96-well plate at a density of $2 \times 10^{5}$ cells $/ \mathrm{mL}$. After $24 \mathrm{~h}$, the culture medium (Dulbecco's Modified Eagle Medium supplemented with 10\% FBS) was removed and replaced by the collected bFGF release medium that was supplemented with $0.5 \%$ FBS. Cell viability was 
measured by MTT assay after $48 \mathrm{~h}$ of culture (n=5) [68]. The release medium collected from the hydrogel without $\mathrm{bFGF}$, and $1 \mathrm{ng} / \mathrm{mL}$ bFGF solution were used as controls ( $\mathrm{n}=5)$. Relative cell viability was determined by normalizing MTT absorbance of the release medium from the hydrogel with bFGF to that of the release medium from the hydrogel without bFGF.

\subsection{Mesenchymal stem cell (MSC) culture and encapsulation of MSCs into bFGF loaded hydrogel}

Rat bone marrow MSCs were cultured in alpha modified minimum essential medium ( $\alpha \mathrm{MEM})$ supplemented with 10\% FBS and 1\% antibiotics. Cells at passages 11-14 were used for encapsulation. Our previous work demonstrated that MSCs of these passages remained multipotency [69]. Before encapsulation, cells were labelled with live cell tracker CM-Dil (Life Technologies) following the protocol provided by the manufacture. To encapsulate MSCs in the hydrogels with or without bFGF, cell suspension was first mixed with the hydrogel solution. The final cell density was 10 million/mL. $200 \mu \mathrm{L}$ of the mixture was then transferred into each Eppendorf tube followed by incubation in a $37^{\circ} \mathrm{C}$ water bath for gelation for $10 \mathrm{~min}$. After removing supernatant, $200 \mu \mathrm{L}$ of low nutrient culture medium ( $\alpha \mathrm{MEM}$ without FBS) was added to each tube. The tubes were cultured in an incubator with $1 \%$ of oxygen. The cell/hydrogel constructs without bFGF and cultured under normal conditions $\left(21 \% \mathrm{O}_{2}\right.$ and $10 \%$ FBS $)$ was used as a control.

\subsection{MSCs survival and proliferation in hydrogel in vitro}

MSC survival in the hydrogels with or without bFGF was assessed by double-stranded DNA (dsDNA, for live cells) content after 1,7 and 14 days of culture ( $n=4$ for each condition at each time point). The cell/hydrogel constructs were first washed with DPBS for 3 times and then digested with papain solution at $60^{\circ} \mathrm{C}$ overnight. The dsDNA concentration was quantified by Quant-iT PicoGreen dsDNA Assay Kit

(Life Technologies). To understand underlying signaling pathways that control bFGF-induced cell 
survival, Western Blotting was performed following standard protocols.[70] In brief, after 7 days of culture, proteins were extracted from the Gel/MSCs and Gel/MSCs/bFGF groups using lysis buffers. The protein samples $(50 \mu \mathrm{g} / \mathrm{lane})$ were then separated by SDS-PAGE followed by transferring to PVDF membranes through electroblotting. The blots were probed with antibodies against protein kinase B (Akt), signal transducer and activator of transcription 3 (STAT3), extracellular-signal-regulated kinases 1/2 (ERK1/2), Kruppel-like factor 4 (KLF4), and $\beta$-actin. The blots were then developed using enhanced chemiluminescence.

MSC paracrine effects in the hydrogels with or without bFGF were characterized at the gene level by real time RT-PCR. After 14 days of culture, cell/hydrogel constructs were immersed in TRIzol (Sigma) to isolate RNA. The total RNA was quantified by Nanodrop (Thermo Fisher Scientific). cDNA was synthesized by utilizing a cDNA high capacity transcription kit (ABI). Real-time RT-PCR was performed with a Mastercycler ep gradient S thermal cycler (Eppendorf) and Platinum Taq DNA Polymerase (Life Tech.) with primers listed in Table 1. A standard $\Delta \Delta \mathrm{Ct}$ method was used to process the data.

Table 1. Primers used for real time RT-PCR.

\begin{tabular}{ccc}
\hline Name & Forward & Reverse \\
\hline$\beta$-actin & AAGATCAAGATCATTGCTCCTC & GGACTCATCGTACTCCTG \\
IGF-1 & TCAGATCACAGCTCCGGAAGC & CTGAGCTGGTGGACGCTCTTC \\
PDGFB & TGTGCTCGGGTCATGTTCAAG & ATTCCTGAGGAACTCTATGAAAT \\
Angpt1 & CCATCTCCGACTTCATATTTTCC & ATGCTCCACACGTGGAGACG \\
\hline
\end{tabular}

\subsection{Implantation of MSCs and hydrogels with or without bFGF into ischemic limbs}

Animal surgeries were performed in compliance with National Institutes of Health and institutional 
guidelines. Male wild type C57BL/6 mice (8 to 10 weeks) were anesthetized with an i.p. injection of ketamine $80 \mathrm{mg} / \mathrm{Kg}$ and xylazine $5 \mathrm{mg} / \mathrm{Kg}$ before all surgical procedures. Hindlimb ischemia was induced by unilateral femoral artery and vein ligation as shown in Scheme 1. The contralateral hindlimb was used as control. Thirty minutes after ligation, injections were made into the gracilis muscle at 4 points (50 $\mu \mathrm{L} /$ injection). The injection groups included hydrogel without bFGF or MSCs (Gel group), hydrogel without bFGF but with MSCs (Gel/MSCs group), hydrogel with bFGF but without MSCs (Gel/bFGF group), and hydrogel with both bFGF and MSCs (Gel/MSCs/bFGF group) ( $\mathrm{n}=5$ for each group). For cell tracking purpose, MSCs were labelled with CM-Dil before injection. The ischemic hindlimbs without injection and normal hindlimbs were used as the negative and positive controls, respectively.

\subsection{Laser Doppler perfusion imaging}

Blood perfusion in ischemic limbs was monitored after induction of ischemia, and 2 and 4 weeks postsurgery using a laser Doppler perfusion imager (Perimed). The ischemic/normal limb blood flow ratio was obtained by dividing the blood perfusion intensity in the ischemic region to the same area in the unoperated contralateral hindlimb [39].

\subsection{Histological assessment of skeletal muscle}

After 4 weeks of injection, muscle tissues ( $n=8$ per time point per injection group) were collected and processed for histological analyses. The samples were fixed with $4 \%$ paraformaldehyde, chemically dehydrated, embedded in paraffin and sectioned into $4 \mu \mathrm{m}$ thick slices in sequence. The samples were then stained with Hematoxylin and Eosin (H\&E), and Masson's Trichrome, respectively. Muscle fiber diameter was quantified from the H\&E images by analysis of 10 random fields of regenerating muscle in the muscle defect using Image J software. Interstitial fibrosis was morphometrically assessed in Masson's Trichrome staining images. 


\subsection{MSC survival and differentiation in ischemic limbs}

To assess cell survival in ischemic limbs, frozen muscle tissues were sectioned into $4 \mu \mathrm{m}$ thick slices. The CM-Dil labelled cells were imaged by Olympus FV1000 filter confocal microscope. Cell density was quantified from 20 randomly selected tissue slices. To determine cell proliferation, and MSC myogenic and endothelial differentiation, immunohistochemical analysis was performed. The tissue slices were fixed in $4 \%$ paraformaldehyde for $1 \mathrm{~h}$, blocked by $10 \%$ goat serum in $0.3 \%$ Triton $\mathrm{X}-100$ for $1 \mathrm{~h}$, and then incubated respectively with primary antibodies of rabbit anti Ki67, mouse anti myosin heavy chain (MHC) and rabbit anti Von Willebrand Factor (vWF) overnight at $37^{\circ} \mathrm{C}$. After rinsing with PBS, the corresponding Dylight488-anti mouse and 647-anti rabbit secondary antibodies were added and incubated for another 1 h. Finally, Hoechst 33342 was used to counterstain the nucleus. Immunofluorescence images were recorded by an Olympus FV1000 filter confocal microscope. Density of the Ki67+ cells was quantified from these images. MSC myogenic and endothelial differentiation was identified as MHC+/CM-Dil+ and vWF+/CM-Dil+ cells, respectively. Blood vessels were identified as tubular structure positively stained for vWF.

\subsection{Statistical analysis}

Data were reported as mean \pm standard deviation. Multivariate repeated-measures ANOVA were performed to test the interactions between different tested groups. A statistical significance was considered when $\mathrm{p}<0.05$. 


\section{Results}

\subsection{Bioactive bFGF can be gradually released from the hydrogel}

The bFGF was able to continuously release from the hydrogel during the 28 -day release period. The release exhibited a two-phase profile, i.e., an initial burst release in the first 5 days followed by a slower release until day 28 (Figure 1A). The bioactivity of the released bFGF was evaluated in terms of its stimulatory effect on fibroblast growth. $1 \mathrm{ng} / \mathrm{mL}$ bFGF solution was used as a control as this concentration significantly stimulated fibroblast growth. The cells cultured in the release medium collected from the hydrogels with bFGF had viability similar to or greater than those cultured in $1 \mathrm{ng} / \mathrm{mL}$ bFGF, and significantly higher than those cultured in release medium from hydrogels without bFGF (Figure 1B). This result demonstrates that the released bFGF remained bioactive.

\section{2. bFGF release promoted MSC survival and proliferation in the hydrogel under low nutrient and oxygen conditions in vitro}

When MSCs were encapsulated in the hydrogel without bFGF and cultured under normal conditions $\left(10 \%\right.$ FBS and $\left.21 \% \mathrm{O}_{2}\right)$, the cells showed a remarkable proliferation during the 14-day period, judged by their dsDNA content (Figure 2A). To investigate how low nutrient and oxygen conditions affect MSC survival, the hydrogel encapsulated with MSCs was cultured under $0 \%$ FBS and $1 \% \mathrm{O}_{2}$ conditions. A significant cell death was observed during the culture with $60.7 \%$ and $35.1 \%$ of survival after 7 and 14 days, respectively. In the hydrogel encapsulated with both bFGF and MSCs, the cells did not experience significant death after 7 days ( $p>0.05$, Figure 2A). Interestingly, they even proliferated afterwards. These results demonstrate that bFGF promoted MSC survival under low nutrient and oxygen conditions. Live cell images showed that MSCs were homogenously distributed in the hydrogels, and cell density change was consistent with the dsDNA results (Figure 2B). 
To understand the underlying mechanism that bFGF enhanced MSC survival under the low nutrient and oxygen conditions, Western blotting was conducted for MSCs cultured in the hydrogels with and without bFGF. Among the different prosurvival signaling pathways such as Akt, Erk1/2, KLF4, and STAT3, KLF4 was found to be upregulated (Figure 3).

\section{3. bFGF release enhanced MSC paracrine effects under low nutrient and oxygen conditions}

The effect of bFGF release on MSC paracrine effects under low nutrient and oxygen conditions was characterized at the gene level by real time RT-PCR. Figure 4 demonstrates that bFGF release significantly enhanced MSC paracrine effects. MSCs encapsulated in the hydrogel with bFGF exhibited significantly higher expressions of angiogenic growth factor Angpt 1 and prosurvival/promyogenic growth factor IGF-1 than those in the hydrogels without bFGF $(\mathrm{p}<0.05)$.

\section{4. bFGF release enhanced MSC survival and differentiation in ischemic limb}

To determine whether bFGF release can enhance MSC survival in vivo, the hydrogel encapsulated with CM-Dil-labeled MSCs (Gel/MSCs group), and hydrogel encapsulated with bFGF and CM-Dil-labeled MSCs (Gel/MSCs/bFGF group) were injected into hindlimb after induction of ischemia. Live cell images showed that a greater density of CM-Dil+ live cells appeared in the Gel/MSCs/bFGF group (Figure 5A). The live cell density in the Gel/MSCs/bFGF group was $~ 3.6$ times of that in the Gel/MSCs group $(\mathrm{p}<0.01$, Figure 5B). These results demonstrate that MSC transplantation with bFGF release significantly increased cell survival in the ischemic limbs.

MSCs have the potential to differentiate into skeletal muscle and endothelial cells to participate in ischemic limb regeneration $[40,41]$. To investigate whether the transplanted MSCs differentiated into 
these lineages, immunohistochemical analysis was performed on tissue sections. Figure 6 demonstrates that some of the MSCs integrated with the tissues and differentiated into both lineages after 4 weeks of injection. In the Gel/MSCs group, only few cells differentiated into vWF+ endothelial cells, and no obvious myogenic differentiation was observed. In the Gel/MSCs/bFGF group, some of the cells differentiated into endothelial cells and participated in blood vessel formation, while more cells differentiated into MHC+ skeletal muscle cells and exhibited a distinctive banding pattern.

\subsection{Delivery of MSCs with bFGF promoted host cell proliferation in ischemic limb}

To determine how the injection of hydrogel (Gel group), hydrogel with bFGF (Gel/bFGF group), hydrogel with MSCs (Gel/MSCs group), and hydrogel with both bFGF and MSCs (Gel/bFGF/MSCs group) affects the cells in the host tissues, immunohistochemical staining of proliferation-associated protein Ki67 was performed (Figure 7). Abundant expression of Ki67 was detected in tissues injected with Gel/MSCs, Gel/bFGF, and Gel/MSCs/bFGF after 4 weeks, while a less-pronounced increase was observed in the tissue injected with Gel group. The injection of Gel/MSCs/bFGF resulted in the most significant Ki67 expression compared to the Gel/MSCs and Gel/bFGF groups ( $\mathrm{p}<0.05$ to Gel/MSCs and $\mathrm{Gel} / \mathrm{bFGF})$.

\subsection{Delivery of MSCs and bFGF stimulated muscle regeneration and tissue vascularization, and decreased fibrosis in ischemic limb}

Induction of ischemia in the hindlimbs led to remarkable muscle degeneration as muscle fibers became largely separated (Figure 8A). Injection of hydrogel (Gel group), hydrogel with bFGF (Gel/bFGF group), and hydrogel with MSCs (Gel/MSCs group) reduced the degree of muscle fiber separation. Interestingly, injection of hydrogel with both bFGF and MSCs (Gel/bFGF/MSCs group) completely averted muscle fibers from separating. 
Muscle fiber size changed during the degeneration (Figure 8A). The mean muscle fiber diameters determined from H\&E images were used to quantify the change (Figure 8B). The non-injection group had remarkably lower diameter than the normal muscle in the non-surgery group $(\mathrm{p}<0.01)$. Injection of Gel group slightly increased the diameter ( $p>0.5$, Gel vs. Non-injection). In contrast, injection of Gel/MSCs and Gel/bFGF groups significantly elevated the muscle fiber diameter $(\mathrm{p}<0.01)$, with $35 \%$ and $44 \%$ of increase, respectively. The most significant increase was found for Gel/MSCs/bFGF group where muscle fiber diameter was similar to that of the normal muscle ( $p>0.1)$, and significantly greater than that of the Gel/MSCs and Gel-only groups $(\mathrm{p}<0.05)$.

The interstitial fibrosis was associated with the injured muscles (Figure 8C). In the non-injection group, the muscles developed substantial fibrosis. The muscles treated with Gel/MSCs and Gel/bFGF groups showed decreased fibrosis. An even more-pronounced reduction of fibrosis was observed in the Gel/MSCs/bFGF group.

A laser Doppler perfusion imaging system was used to quantify blood perfusion change in ischemic limbs with or without treatment (Figure 9A). The regional blood flow was reduced dramatically after induction of ischemia (Figure 9). Without treatment, the ischemic limb slowly increased blood perfusion with $40.4 \%$ of recovery after 4 weeks. Injection of Gel significantly stimulated vascularization with $60.7 \%$ of blood perfusion recovery $(\mathrm{p}<0.5)$. Incorporation of MSCs in the hydrogel (Gel/MSCs group) only substantially enhanced blood perfusion recovery compared to the Gel group ( $p>0.5)$. In contrast, the bFGF releasing Gel/bFGF group more efficiently recovered blood perfusion with $84.3 \%$ of recovery after 4 weeks. The fastest blood perfusion recovery was found in the Gel/MSCs/bFGF group, where the blood perfusion reached normal level after only 2 weeks of injection. 
Blood vessel density in the muscle was quantified to further determine tissue vascularization with or without treatment (Figure 10). After 4 weeks of injection, vessel density in the Gel group was substantially greater than the non-injection group ( $>$ >0.5). Injection of Gel/MSCs and Gel/bFGF groups significantly increased vessel densities $(\mathrm{p}<0.05)$, and the Gel/bFGF group demonstrated significantly greater vessel density than the Gel/MSCs group $(\mathrm{p}<0.05)$. Consistent with the blood perfusion results, the vessel density in the Gel/MSCs/bFGF group was similar to that in the normal muscles after 4 weeks $(\mathrm{p}>0.1)$.

\section{Discussion}

The objective of this work was to develop a stem cell delivery system that augments cell survival under ischemic conditions, thus enhancing ischemic limb regeneration. Ischemic limbs are characterized by a low nutrient and oxygen, and poorly vascularized environment. Inferior cell survival in this environment is one of the key causes that are responsible for the low therapeutic efficacy of stem cell therapy. Augmentation of cell survival under these harsh conditions represents a critical need to improve the efficacy. In this work, we hypothesized that a stem cell delivery system with the following properties will significantly augment cell survival: 1) it has a prosurvival environment to promote cell survival before vascularization is established, and 2) it possesses a proangiogenic environment to quickly vascularize the ischemic limb to improve long-term cell survival.

The created delivery system was based on MSCs, a degradable and thermosensitive hydrogel, and bFGF. MSCs have been shown to differentiate into skeletal muscle and endothelial cells necessary for ischemic limb regeneration $[40,41,71]$. The degradable and thermosensitive hydrogel served as cell carrier. The benefit of using this type of hydrogel is that gelation is controlled simply by temperature without using 
crosslinkers that may initiate toxicity. In addition, the fast gelation rate enables the hydrogel to quickly immobilize in the tissue after injection so as to efficiently hold cells, leading to high cell retention [65]. bFGF is a prosurvival and proangiogenic growth factor $[58,62,66,72,73]$. In this system, bFGF is encapsulated in the hydrogel. It can thus gradually release from the hydrogel (Figures 1). The released bFGF not only promotes stem cell survival but also stimulates angiogenesis.

The MSCs encapsulated in the hydrogel experienced extensive death when cultured in the low nutrient and oxygen conditions in vitro with $60.7 \%$ and $35.1 \%$ survival after 7 and 14 days, respectively (Figure 2A). Addition of bFGF in the hydrogel significantly increased MSC survival in the first 7 days as no significant cell death was found (Figure 2A). The cells even proliferated afterwards. Consistent with in vitro results, the released bFGF significantly enhanced MSC survival in the ischemic limb (Figure 5). The density of surviving MSCs was increased by $~ 3.6$ times over the MSC transplantation without bFGF (Gel/MSCs group). Besides promoting MSC survival and proliferation, the released bFGF stimulated host cell proliferation in the ischemic limb as the density of Ki67+ cells in the Gel/bFGF group was significantly higher than that in the Gel and non-injection groups (Figure 7). These results are consistent with those reported previously that bFGF can inhibit apoptosis of osteoblasts[74] and endothelial cells [75] under ischemic conditions. In these reports, the improved cell survival is a result of bFGF activating osteoblast PI3k/Akt pathway[74] and endothelial cell hypoxia-induced factor-1 (HIF-1) pathway [75], respectively. In this work, we demonstrated that the prosurvival effect on MSCs is due to bFGF activating KLF4 pathway, an important protective factor in disease states and mediator to nitric oxide in ischemic tissues (Figure 3).

Release of bFGF alone without using MSCs (Gel/bFGF group) had a significant influence on ischemic limb vascularization (Figures 9 and 10). After 2 and 4 weeks of injection, blood perfusion was dramatically increased compared to the hydrogel only group (Gel group). Consistent with blood perfusion 
results, the blood vessel density of the Gel/bFGF group was significantly higher than that of the Gel group (Figure 10). These results are in accord with previous report that bFGF releasing gelatin-PLGA hydrogels stimulated blood reperfusion recovery in a murine critical limb ischemic model [61]. The enhanced vascularization is likely attributed to the angiogenic effect of bFGF. Controlled release of bFGF from the hydrogel has the advantage of continuously supplying bioactive bFGF for angiogenesis without the need for repeated administration due to its short half live. It is also possible that bFGF salvaged the host vascular cells as it did for MSCs. Besides promoting vascularization, the released bFGF enhanced muscle regeneration as demonstrated in Figure 8, where the average muscle fiber diameter was increased by $20 \%$ compared to the Gel group. bFGF has been shown to promote skeletal muscle regeneration by stimulating skeletal muscle cell proliferation [59, 62]. Our results in Figure 7 indirectly confirmed this effect as the number of proliferating cells was significantly higher in the Gel/bFGF group.

Delivery of MSCs with hydrogel (Gel/MSCs group) slightly enhanced blood perfusion recovery and muscle regeneration compared to the delivery of hydrogel alone (Gel group). This is judged from the substantially increased blood perfusion (Figure 9), blood vessel density (Figure 10), and average muscle fiber diameter (Figure 8). The improvement is likely the contribution of MSCs survived in the ischemic limb. These cells can differentiate into endothelial cells (Figure 6). They may also provide paracrine effects for vascularization and muscle regeneration. MSCs are known to secrete angiogenic growth factors like VEGF, bFGF and PDGF for vascularization, and IGF-1 for promyogenesis [76, 77]. However, since the cell survival in this group is low (Figure 5), the improvement on blood perfusion recovery and muscle regeneration was limited.

The remarkable blood perfusion recovery and muscle regeneration were found for Gel/MSCs/bFGF group. The blood perfusion was fully recovered only after 2 weeks of injection (Figure 9), suggesting that the ischemia was quickly and completely alleviated. This result was validated by blood vessel densities in 
the recovered and normal limbs, where both limbs had the same density (Figure 10). The Gel/MSCs/bFGF group also exhibited remarkably improved muscle regeneration. The mean muscle fiber diameter was similar to that of the normal limbs after 4 weeks. The enhanced blood perfusion recovery and muscle regeneration over Gel/MSCs and Gel/bFGF groups can be attributed to the increased MSC survival, differentiation, and paracrine effects. We have demonstrated in Figure 5 that MSC survival was significantly augmented with the encapsulation of bFGF in the hydrogel. This allowed a greater number of MSCs to differentiate into skeletal muscle and endothelial cells to participate in muscle regeneration and vascularization, respectively (Figure 6). Delivery of MSCs with bFGF can increase cell paracrine effects. Figure 4 shows that the expression of angiogenic factor Angpt-1 and promyogenic factor IGF-1 was significantly upregulated. These growth factors promote both vascularization and muscle regeneration. Furthermore, the enhanced paracrine effects can rescue the host cells and increase their proliferation (Figure 7), which may further facilitate vascularization and muscle regeneration. Collectively, this study demonstrates that a stem cell delivery system that augments both short- and longterm cell survival under ischemic conditions can quickly recover blood perfusion and promote skeletal muscle regeneration in the ischemic limbs.

\section{Conclusions}

In this work, a stem cell delivery system capable of augmenting cell survival in ischemic limbs was created for quick recovery of blood perfusion and enhancing skeletal muscle regeneration. The delivery system was based on an injectable, biodegradable, and thermosensitive hydrogel, bFGF, and MSCs. When tested under low nutrient and oxygen conditions in vitro, the system significantly increased cell survival and paracrine effects. When transplanted in the ischemic limbs, the system not only promoted MSC survival, but also stimulated quick vascularization. The engrafted MSCs were differentiated into skeletal 
muscle and endothelial cells. The blood perfusion was completely recovered after 2 weeks, and the average muscle fiber diameter was similar to that of the normal limb after 4 weeks. This stem cell delivery system may provide a therapeutic option for treatment of a variety of tissue damages caused by ischemia.

\section{Acknowledgements}

The assistance of Dr. Jianjie Ma's group and Dr. Matthew Joseph is greatly appreciated. This work was supported by US National Science Foundation (1006734 and 1160122), American Heart Association (15GRNT25830058 and 13GRNT17150041), National Science Foundation of China (81471788), and Institute for Materials Research seed grant at The Ohio State University. 


\section{References:}

[1] Gupta NK, Armstrong EJ, Parikh SA. The current state of stem cell therapy for peripheral artery disease. Current cardiology reports. 2014;16:447.

[2] Norgren L, Hiatt WR, Dormandy JA, Nehler MR, Harris KA, Fowkes FG, et al. Inter-society consensus for the management of peripheral arterial disease. International angiology : a journal of the International Union of Angiology. 2007;26:81-157.

[3] Alev C, Ii M, Asahara T. Endothelial progenitor cells: a novel tool for the therapy of ischemic diseases. Antioxidants \& redox signaling. 2011;15:949-65.

[4] Benoit E, O'Donnell TF, Patel AN. Safety and efficacy of autologous cell therapy in critical limb ischemia: a systematic review. Cell transplantation. 2013;22:545-62.

[5] Hart CA, Tsui J, Khanna A, Abraham DJ, Baker DM. Stem cells of the lower limb: their role and potential in management of critical limb ischemia. Experimental biology and medicine (Maywood, NJ). 2013;238:1118-26.

[6] Jadlowiec C, Brenes RA, Li X, Lv W, Protack CD, Collins MJ, et al. Stem cell therapy for critical limb ischemia: what can we learn from cell therapy for chronic wounds? Vascular. 2012;20:284-9.

[7] Liew A, O'Brien T. Therapeutic potential for mesenchymal stem cell transplantation in critical limb ischemia. Stem cell research \& therapy. 2012;3:28.

[8] Raval Z, Losordo DW. Cell therapy of peripheral arterial disease: from experimental findings to clinical trials. Circulation research. 2013;112:1288-302.

[9] Bradbury AW, Adam DJ, Bell J, Forbes JF, Fowkes FG, Gillespie I, et al. Bypass versus Angioplasty in Severe Ischaemia of the Leg (BASIL) trial: A survival prediction model to facilitate clinical decision making. Journal of vascular surgery. 2010;51:52s-68s.

[10] Conte MS. Bypass versus Angioplasty in Severe Ischaemia of the Leg (BASIL) and the (hoped for) dawn of evidence-based treatment for advanced limb ischemia. Journal of vascular surgery. 2010;51:69s-75s.

[11] Borselli C, Storrie H, Benesch-Lee F, Shvartsman D, Cezar C, Lichtman JW, et al. Functional muscle regeneration with combined delivery of angiogenesis and myogenesis factors. Proceedings of the National Academy of Sciences of the United States of America. 2010;107:3287-92.

[12] Liew A, O'Brien T. Therapeutic potential for mesenchymal stem cell transplantation in critical limb ischemia. Stem Cell Res Ther. 2012;3.

[13] Tateishi-Yuyama E, Matsubara H, Murohara T, Ikeda U, Shintani S, Masaki H, et al. Therapeutic angiogenesis for patients with limb ischaemia by autologous transplantation of bone-marrow cells: a pilot study and a randomised controlled trial. Lancet. 2002;360:427-35. [14] Iwase T, Nagaya N, Fujii T, Itoh T, Murakami S, Matsumoto T, et al. Comparison of angiogenic potency between mesenchymal stem cells and mononuclear cells in a rat model of hindlimb ischemia. Cardiovasc Res. 2005;66:543-51.

[15] Yan JL, Tie GD, Xu TY, Cecchini K, Messina LM. Mesenchymal Stem Cells as a Treatment for Peripheral Arterial Disease: Current Status and Potential Impact of Type II Diabetes on Their Therapeutic Efficacy. Stem Cell Rev Rep. 2013;9:360-72.

[16] Rufaihah AJ, Huang NF, Jame S, Lee JC, Nguyen HN, Byers B, et al. Endothelial Cells Derived From Human iPSCS Increase Capillary Density and Improve Perfusion in a Mouse Model of Peripheral Arterial Disease. Arterioscl Throm Vas. 2011;31:E72-U44.

[17] Boldrin L, Elvassore N, Malerba A, Flaibani M, Cimetta E, Piccoli M, et al. Satellite cells delivered by micro-patterned scaffolds: a new strategy for cell transplantation in muscle diseases. Tissue Eng. 2007;13:253-62.

[18] Serena E, Flaibani M, Carnio S, Boldrin L, Vitiello L, De Coppi P, et al. Electrophysiologic 
stimulation improves myogenic potential of muscle precursor cells grown in a $3 \mathrm{D}$ collagen scaffold. Neurological research. 2008;30:207-14.

[19] Hwang JH, Kim IG, Piao S, Jung AR, Lee JY, Park KD, et al. Combination therapy of human adipose-derived stem cells and basic fibroblast growth factor hydrogel in muscle regeneration. Biomaterials. 2013;34:6037-45.

[20] Shvartsman D, Storrie-White H, Lee K, Kearney C, Brudno Y, Ho N, et al. Sustained Delivery of VEGF Maintains Innervation and Promotes Reperfusion in Ischemic Skeletal Muscles Via NGF/GDNF Signaling. Mol Ther. 2014;22:1243-53.

[21] Banfi A, von Degenfeld G, Blau HM. Critical role of microenvironmental factors in angiogenesis. Current atherosclerosis reports. 2005;7:227-34.

[22] Walgenbach KJ, Gratas C, Shestak KC, Becker D. Ischemia-Induced Expression of Bfgf in Normal Skeletal-Muscle - a Potential Paracrine Mechanism for Mediating Angiogenesis in Ischemic Skeletal-Muscle. Nat Med. 1995;1:453-9.

[23] Johnson SE, Allen RE. The Effects of Bfgf, Igf-I, and Tgf-Beta on Rmo Skeletal-Muscle CellProliferation and Differentiation. Exp Cell Res. 1990;187:250-4.

[24] Hammers DW, Sarathy A, Pham CB, Drinnan CT, Farrar RP, Suggs LJ. Controlled release of IGF-I from a biodegradable matrix improves functional recovery of skeletal muscle from ischemia/reperfusion. Biotechnol Bioeng. 2012;109:1051-9.

[25] Lu DB, Chen B, Liang ZW, Deng WQ, Jiang YZ, Li SF, et al. Comparison of bone marrow mesenchymal stem cells with bone marrow-derived mononuclear cells for treatment of diabetic critical limb ischemia and foot ulcer: A double-blind, randomized, controlled trial. Diabetes Res Clin Pr. 2011;92:26-36.

[26] Darabi R, Gehlbach K, Bachoo RM, Kamath S, Osawa M, Kamm KE, et al. Functional skeletal muscle regeneration from differentiating embryonic stem cells. Nat Med. 2008;14:13443 .

[27] Altaner C, Altanerova V, Cihova M, Hunakova L, Kaiserova K, Klepanec A, et al. Characterization of Mesenchymal Stem Cells of "No-Options" Patients with Critical Limb Ischemia Treated by Autologous Bone Marrow Mononuclear Cells. Plos One. 2013;8.

[28] Gupta PK, Chullikana A, Parakh R, Desai S, Das A, Gottipamula S, et al. A double blind randomized placebo controlled phase I/II study assessing the safety and efficacy of allogeneic bone marrow derived mesenchymal stem cell in critical limb ischemia. J Transl Med. 2013;11.

[29] Miranville A, Heeschen C, Sengenes C, Curat CA, Busse R, Bouloumie A. Improvement of postnatal neovascularization by human adipose tissue-derived stem cells. Circulation. 2004;110:349-55.

[30] Murohara T. Autologous adipose tissue as a new source of progenitor cells for therapeutic angiogenesis. J Cardiol. 2009;53:155-63.

[31] Kondo K, Shintani S, Shibata R, Murakami H, Murakami R, Imaizumi M, et al. Implantation of Adipose-Derived Regenerative Cells Enhances Ischemia-Induced Angiogenesis. Arterioscl Throm Vas. 2009;29:61-U167.

[32] Marino G, Moraci M, Armenia E, Orabona C, Sergio R, De Sena G, et al. Therapy with autologous adipose-derived regenerative cells for the care of chronic ulcer of lower limbs in patients with peripheral arterial disease. J Surg Res. 2013;185:36-44.

[33] Bartel RL, Booth E, Cramer C, Ledford K, Watling S, Zeigler F. From Bench to Bedside: Review of Gene and Cell-Based Therapies and the Slow Advancement into Phase 3 Clinical Trials, with a Focus on Aastrom's Ixmyelocel-T. Stem Cell Rev Rep. 2013;9:373-83.

[34] Capoccia BJ, Robson DL, Levac KD, Maxwell DJ, Hohm SA, Neelamkavil MJ, et al. Revascularization of ischemic limbs after transplantation of human bone marrow cells with high aldehyde dehydrogenase activity. Blood. 2009;113:5340-51.

[35] Li YQ, Liu W, Liu F, Zeng Y, Zuo SM, Feng SY, et al. Primed 3D injectable microniches 
enabling low-dosage cell therapy for critical limb ischemia. Proceedings of the National Academy of Sciences of the United States of America. 2014;111:13511-6.

[36] Leroux L, Descamps B, Tojais NF, Seguy B, Oses P, Moreau C, et al. Hypoxia Preconditioned Mesenchymal Stem Cells Improve Vascular and Skeletal Muscle Fiber Regeneration After Ischemia Through a Wnt4-dependent Pathway. Mol Ther. 2010;18:1545-52.

[37] Borselli C, Storrie H, Benesch-Lee F, Shvartsman D, Cezar C, Lichtman JW, et al. Functional muscle regeneration with combined delivery of angiogenesis and myogenesis factors. Proceedings of the National Academy of Sciences of the United States of America. 2010;107:3287-92.

[38] Hill E, Boontheekul T, Mooney DJ. Regulating activation of transplanted cells controls tissue regeneration. Proceedings of the National Academy of Sciences of the United States of America. 2006;103:2494-9.

[39] Shvartsman D, Storrie-White H, Lee K, Kearney C, Brudno Y, Ho N, et al. Sustained delivery of VEGF maintains innervation and promotes reperfusion in ischemic skeletal muscles via NGF/GDNF signaling. Molecular therapy : the journal of the American Society of Gene Therapy. 2014;22:1243-53.

[40] Leroux L, Descamps B, Tojais NF, Seguy B, Oses P, Moreau C, et al. Hypoxia preconditioned mesenchymal stem cells improve vascular and skeletal muscle fiber regeneration after ischemia through a Wnt4-dependent pathway. Molecular therapy : the journal of the American Society of Gene Therapy. 2010;18:1545-52.

[41] Li Y, Liu W, Liu F, Zeng Y, Zuo S, Feng S, et al. Primed 3D injectable microniches enabling low-dosage cell therapy for critical limb ischemia. Proc Natl Acad Sci U S A. 2014;111:13511-6.

[42] Gupta PK, Chullikana A, Parakh R, Desai S, Das A, Gottipamula S, et al. A double blind randomized placebo controlled phase I/II study assessing the safety and efficacy of allogeneic bone marrow derived mesenchymal stem cell in critical limb ischemia. Journal of translational medicine. 2013;11:143.

[43] Benoit E, O'Donnell TF, Jr., Iafrati MD, Asher E, Bandyk DF, Hallett JW, et al. The role of amputation as an outcome measure in cellular therapy for critical limb ischemia: implications for clinical trial design. Journal of translational medicine. 2011;9:165.

[44] Aranguren XL, Verfaillie CM, Luttun A. Emerging hurdles in stem cell therapy for peripheral vascular disease. Journal of molecular medicine (Berlin, Germany). 2009;87:3-16.

[45] Mamidi MK, Pal R, Dey S, Bin Abdullah BJ, Zakaria Z, Rao MS, et al. Cell therapy in critical limb ischemia: current developments and future progress. Cytotherapy. 2012;14:902-16.

[46] Ouma GO, Zafrir B, Mohler ER, 3rd, Flugelman MY. Therapeutic angiogenesis in critical limb ischemia. Angiology. 2013;64:466-80.

[47] Don CW, Murry CE. Improving survival and efficacy of pluripotent stem cell-derived cardiac grafts. Journal of cellular and molecular medicine. 2013;17:1355-62.

[48] Robey TE, Saiget MK, Reinecke H, Murry CE. Systems approaches to preventing transplanted cell death in cardiac repair. Journal of molecular and cellular cardiology. 2008;45:567-81.

[49] Behfar A, Yamada S, Crespo-Diaz R, Nesbitt JJ, Rowe LA, Perez-Terzic C, et al. Guided cardiopoiesis enhances therapeutic benefit of bone marrow human mesenchymal stem cells in chronic myocardial infarction. Journal of the American College of Cardiology. 2010;56:721-34.

[50] Pasha Z, Wang Y, Sheikh R, Zhang D, Zhao T, Ashraf M. Preconditioning enhances cell survival and differentiation of stem cells during transplantation in infarcted myocardium. Cardiovascular research. 2008;77:134-42.

[51] van Laake LW, van Donselaar EG, Monshouwer-Kloots J, Schreurs C, Passier R, Humbel BM, et al. Extracellular matrix formation after transplantation of human embryonic stem cellderived cardiomyocytes. Cellular and molecular life sciences : CMLS. 2010;67:277-90. 
[52] Samper E, Diez-Juan A, Montero JA, Sepulveda P. Cardiac cell therapy: boosting mesenchymal stem cells effects. Stem cell reviews. 2013;9:266-80.

[53] Laflamme MA, Chen KY, Naumova AV, Muskheli V, Fugate JA, Dupras SK, et al. Cardiomyocytes derived from human embryonic stem cells in pro-survival factors enhance function of infarcted rat hearts. Nature biotechnology. 2007;25:1015-24.

[54] Christman KL, Vardanian AJ, Fang Q, Sievers RE, Fok HH, Lee RJ. Injectable fibrin scaffold improves cell transplant survival, reduces infarct expansion, and induces neovasculature formation in ischemic myocardium. Journal of the American College of Cardiology. 2004;44:654-60.

[55] Kutschka I, Chen IY, Kofidis T, Arai T, von Degenfeld G, Sheikh AY, et al. Collagen matrices enhance survival of transplanted cardiomyoblasts and contribute to functional improvement of ischemic rat hearts. Circulation. 2006;114:I167-73.

[56] Lu S, Wang H, Lu W, Liu S, Lin Q, Li D, et al. Both the transplantation of somatic cell nuclear transfer- and fertilization-derived mouse embryonic stem cells with temperatureresponsive chitosan hydrogel improve myocardial performance in infarcted rat hearts. Tissue engineering Part A. 2010;16:1303-15.

[57] Cheng K, Blusztajn A, Shen D, Li TS, Sun B, Galang G, et al. Functional performance of human cardiosphere-derived cells delivered in an in situ polymerizable hyaluronan-gelatin hydrogel. Biomaterials. 2012;33:5317-24.

[58] Chung JH, Im EK, Jin T, Lee SM, Kim SH, Choi EY, et al. Cathepsin L derived from skeletal muscle cells transfected with bFGF promotes endothelial cell migration. Exp Mol Med. 2011;43:179-88.

[59] Lefaucheur JP, Sebille A. Basic fibroblast growth factor promotes in vivo muscle regeneration in murine muscular dystrophy. Neuroscience letters. 1995;202:121-4.

[60] Sieber CC, Sumanovski LT, Stumm M, van der Kooij M, Battegay E. In vivo angiogenesis in normal and portal hypertensive rats: role of basic fibroblast growth factor and nitric oxide. $\mathrm{J}$ Hepatol. 2001;34:644-50.

[61] Layman H, Spiga MG, Brooks T, Pham S, Webster KA, Andreopoulos FM. The effect of the controlled release of basic fibroblast growth factor from ionic gelatin-based hydrogels on angiogenesis in a murine critical limb ischemic model. Biomaterials. 2007;28:2646-54.

[62] Guthridge M, Wilson M, Cowling J, Bertolini J, Hearn MT. The role of basic fibroblast growth factor in skeletal muscle regeneration. Growth factors. 1992;6:53-63.

[63] Brimah K, Ehrhardt J, Mouly V, Butler-Browne GS, Partridge TA, Morgan JE. Human muscle precursor cell regeneration in the mouse host is enhanced by growth factors. Hum Gene Ther. 2004;15:1109-24.

[64] Ma Z, Nelson DM, Hong Y, Wagner WR. Thermally responsive injectable hydrogel incorporating methacrylate-polylactide for hydrolytic lability. Biomacromolecules. 2010;11:1873-81.

[65] Li Z, Wang F, Roy S, Sen CK, Guan J. Injectable, highly flexible, and thermosensitive hydrogels capable of delivering superoxide dismutase. Biomacromolecules. 2009;10:3306-16.

[66] Faham S, Hileman RE, Fromm JR, Linhardt RJ, Rees DC. Heparin structure and interactions with basic fibroblast growth factor. Science. 1996;271:1116-20.

[67] Pang YG, Wang XL, Ucuzian AA, Brey EM, Burgess WH, Jones KJ, et al. Local delivery of a collagen-binding FGF-1 chimera to smooth muscle cells in collagen scaffolds for vascular tissue engineering. Biomaterials. 2010;31:878-85.

[68] Ormsby R, McNally T, O'Hare P, Burke G, Mitchell C, Dunne N. Fatigue and biocompatibility properties of a poly(methyl methacrylate) bone cement with multi-walled carbon nanotubes. Acta Biomater. 2012;8:1201-12.

[69] Guan J, Wang F, Li Z, Chen J, Guo X, Liao J, et al. The stimulation of the cardiac 
differentiation of mesenchymal stem cells in tissue constructs that mimic myocardium structure and biomechanics. Biomaterials. 2011;32:5568-80.

[70] Liu ZQ, Mahmood T, Yang PC. Western blot: technique, theory and trouble shooting. North American journal of medical sciences. 2014;6:160.

[71] Meligy FY, Shigemura K, Behnsawy HM, Fujisawa M, Kawabata M, Shirakawa T. The efficiency of in vitro isolation and myogenic differentiation of MSCs derived from adipose connective tissue, bone marrow, and skeletal muscle tissue. In Vitro Cell Dev Biol Anim. 2012;48:203-15.

[72] Damien CJ, Christel PS, Benedict JJ, Patat JL, Guillemin G. A Composite of Natural Coral, Collagen, Bone Protein and Basic Fibroblast Growth-Factor Tested in a Rat Subcutaneous Model. Ann Chir Gynaecol Fe. 1993;82:117-28.

[73] Li ZQ, Guo XL, Guan JJ. A Thermosensitive Hydrogel Capable of Releasing bFGF for Enhanced Differentiation of Mesenchymal Stem Cell into Cardiomyocyte-like Cells under Ischemic Conditions. Biomacromolecules. 2012;13:1956-64.

[74] Park SJ, Kim SH, Choi HS, Rhee Y, Lim SK. Fibroblast growth factor 2-induced cytoplasmic asparaginyl-tRNA synthetase promotes survival of osteoblasts by regulating anti-apoptotic PI3K/Akt signaling. Bone. 2009;45:994-1003.

[75] Bolitho $\mathrm{C}, \mathrm{Xu} \mathrm{W}$, Zoellner $\mathrm{H}$. Negative feedback for endothelial apoptosis: a potential physiological role for fibroblast growth factor. Journal of vascular research. 2008;45:193-204.

[76] Kim I, Lee SK, Yoon JI, Kim da E, Kim M, Ha H. Fibrin glue improves the therapeutic effect of MSCs by sustaining survival and paracrine function. Tissue Eng Part A. 2013;19:2373-81.

[77] Salvolini E, Orciani M, Vignini A, Mattioli-Belmonte M, Mazzanti L, Di Primio R. Skinderived mesenchymal stem cells (S-MSCs) induce endothelial cell activation by paracrine mechanisms. Exp Dermatol. 2010;19:848-50. 


\section{Figure Captions}

Scheme 1. Induction of hindlimb ischemia by unilateral femoral artery and vein ligation.

Figure 1. A) Release kinetics of bFGF. The hydrogel was encapsulated with $1 \mathrm{mg} / \mathrm{mL}$ of heparin and 50 $\mu \mathrm{g} / \mathrm{mL}$ of bFGF. The release was conducted at $37^{\circ} \mathrm{C}$ for 4 weeks. B) Bioactivity of the released bFGF. The bioactivity of bFGF was assessed in terms of its stimulative effect on rat fibroblast proliferation. The release medium collected from the hydrogel without bFGF, and $1 \mathrm{ng} / \mathrm{mL}$ bFGF solution were used as controls.

Figure 2. A) dsDNA content and B) Live cell images of MSCs encapsulated in hydrogel without bFGF (Gel/MSCs) or with bFGF (Gel/MSCs/bFGF), and cultured under either normal $\left(10 \% \mathrm{FBS}, 1 \% \mathrm{O}_{2}\right)$ or low nutrient and oxygen $\left(0 \% \mathrm{FBS}, 1 \% \mathrm{O}_{2}\right)$ conditions. ${ }^{*} \mathrm{p}<0.05 .{ }^{* *} \mathrm{p}<0.01$.

Figure 3. bFGF released from the hydrogel activated KLF4 survival signaling protein. MSCs were encapsulated in hydrogel without bFGF (Gel/MSCs) or with bFGF (Gel/MSCs/bFGF), and cultured under low nutrient and oxygen conditions $\left(0 \% \mathrm{FBS}, 1 \% \mathrm{O}_{2}\right)$.

Figure 4. Paracrine effects of MSCs encapsulated in hydrogel without bFGF (Gel/MSCs) or with bFGF (Gel/MSCs/bFGF), and cultured under low nutrient and oxygen conditions $\left(0 \% \mathrm{FBS}, 1 \% \mathrm{O}_{2}\right)$. Gene expression of Angpt-1 and IGF-1 was significantly upregulated in the Gel/MSCs/bFGF group. ${ }^{*} \mathrm{p}<0.05 . * *$ $\mathrm{p}<0.01$. 
Figure 5. MSC survival in ischemic limbs after 4 weeks of implantation. Cells were labeled with live cell tracker CM-Dil before implantation. A) Live cell images in Gel/MSCs and Gel/MSCs/bFGF groups; B) Density of live MSCs calculated from live cell images. ${ }^{*} \mathrm{p}<0.05$.

Figure 6. Differentiation of transplanted MSCs in ischemic limbs after 4 weeks of transplantation. Few CMDil positive MSCs in the Gel/MSCs group were differentiated into endothelial cells. Some of the MSCs in the Gel/MSCs/bFGF group differentiated into endothelial cells while more cells differentiated into skeletal muscle cells and exhibited a distinctive banding pattern.

Figure 7. Ki67 expression in ischemic limbs 4 weeks after implantation of Gel, Gel/MSCs, Gel/bFGF, and Gel/MSCs/bFGF. Non-injection group was used as control. A. Ki67 staining images; B. Ki67+ cell density. * $\mathrm{p}<0.05 . * * \mathrm{p}<0.01$.

Figure 8. H\&E staining (A), average muscle fiber diameter (B) and Masson's trichrome staining (C) of ischemic limbs 4 weeks after implantation of Gel, Gel/MSCs, Gel/bFGF, and Gel/MSCs/bFGF groups. Noninjection group was used as control. ${ }^{*} \mathrm{p}<0.05 .{ }^{* *} \mathrm{p}<0.01$.

Figure 9. Blood perfusion of ischemic limbs at day 0, and weeks 2 and 4 for non-injection, Gel, Gel/MSCs, $\mathrm{Gel} / \mathrm{bFGF}$, and Gel/MSCs/bFGF groups. A) laser Doppler perfusion images; B) ratio of blood perfusion at different time points. ${ }^{*} \mathrm{p}<0.05$. ${ }^{* *} \mathrm{p}<0.01$.

Figure 10. vWF staining (A) and blood vessel density (B) of ischemic limbs 4 weeks after implantation of $\mathrm{Gel}, \mathrm{Gel} / \mathrm{MSCs}, \mathrm{Gel} / \mathrm{bFGF}$, and Gel/MSCs/bFGF. Non-injection group was used as control. * $\mathrm{p}<0.05$. ** $\mathrm{p}<0.01$. 


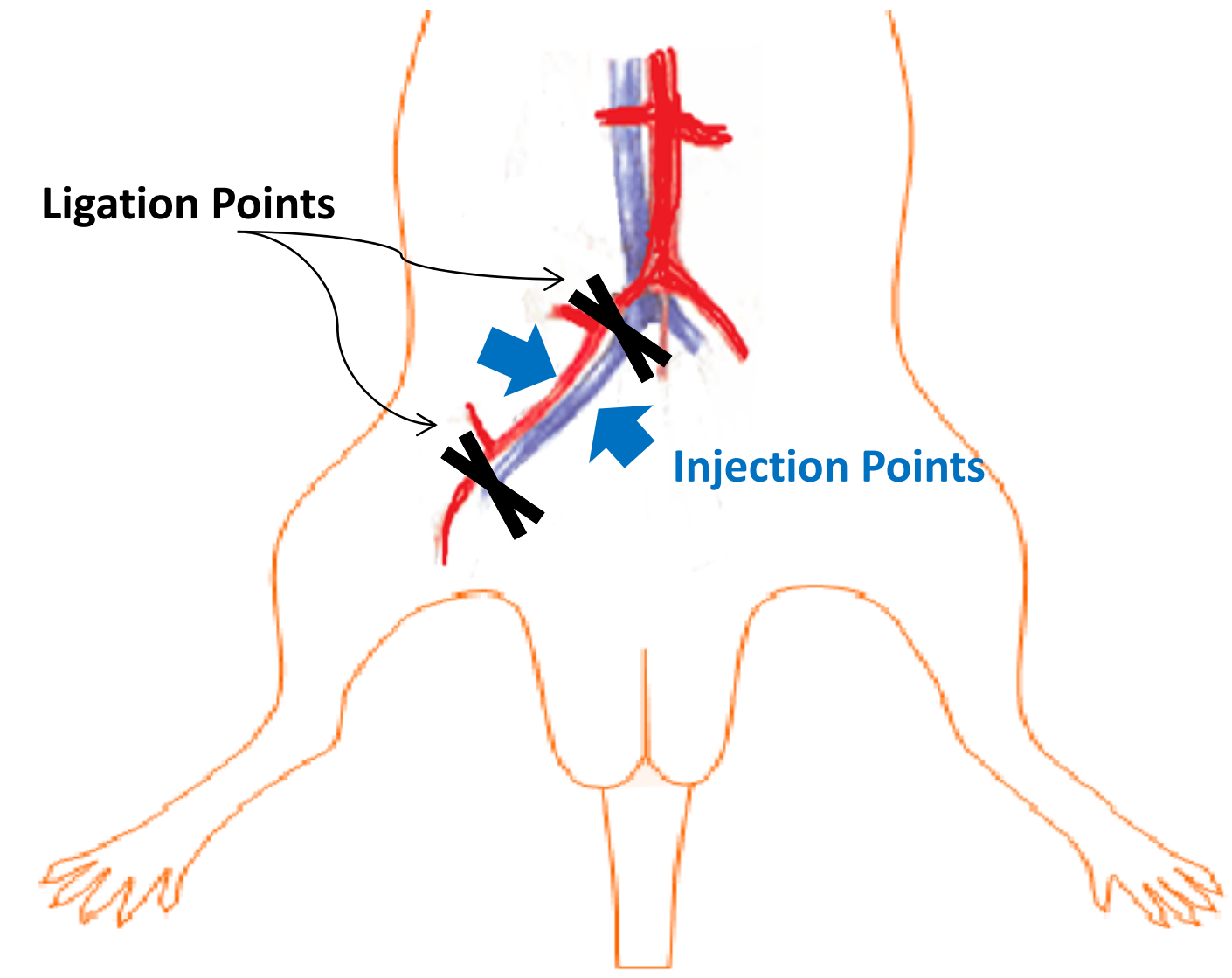

Scheme 1 


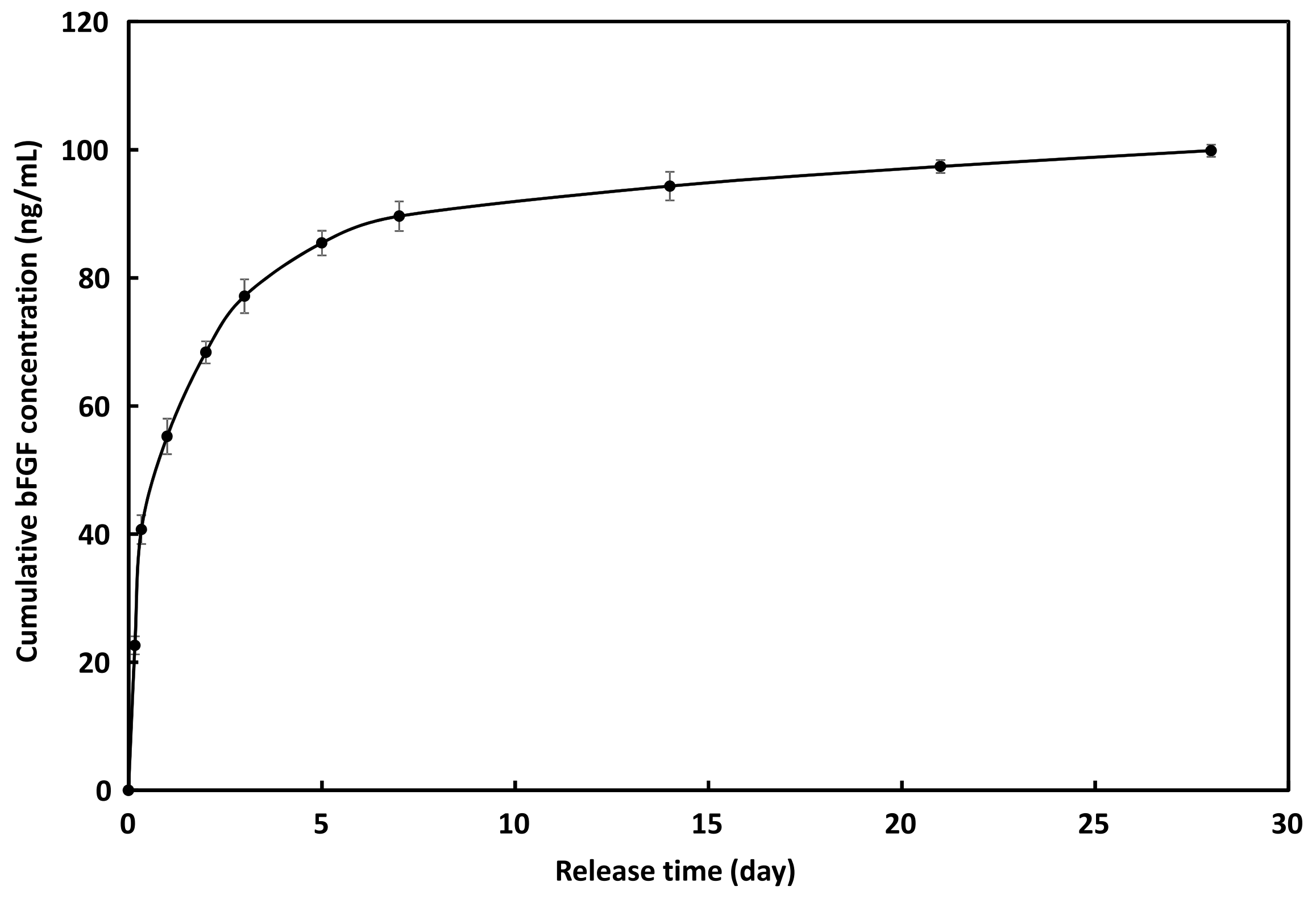

Figure 1.A 


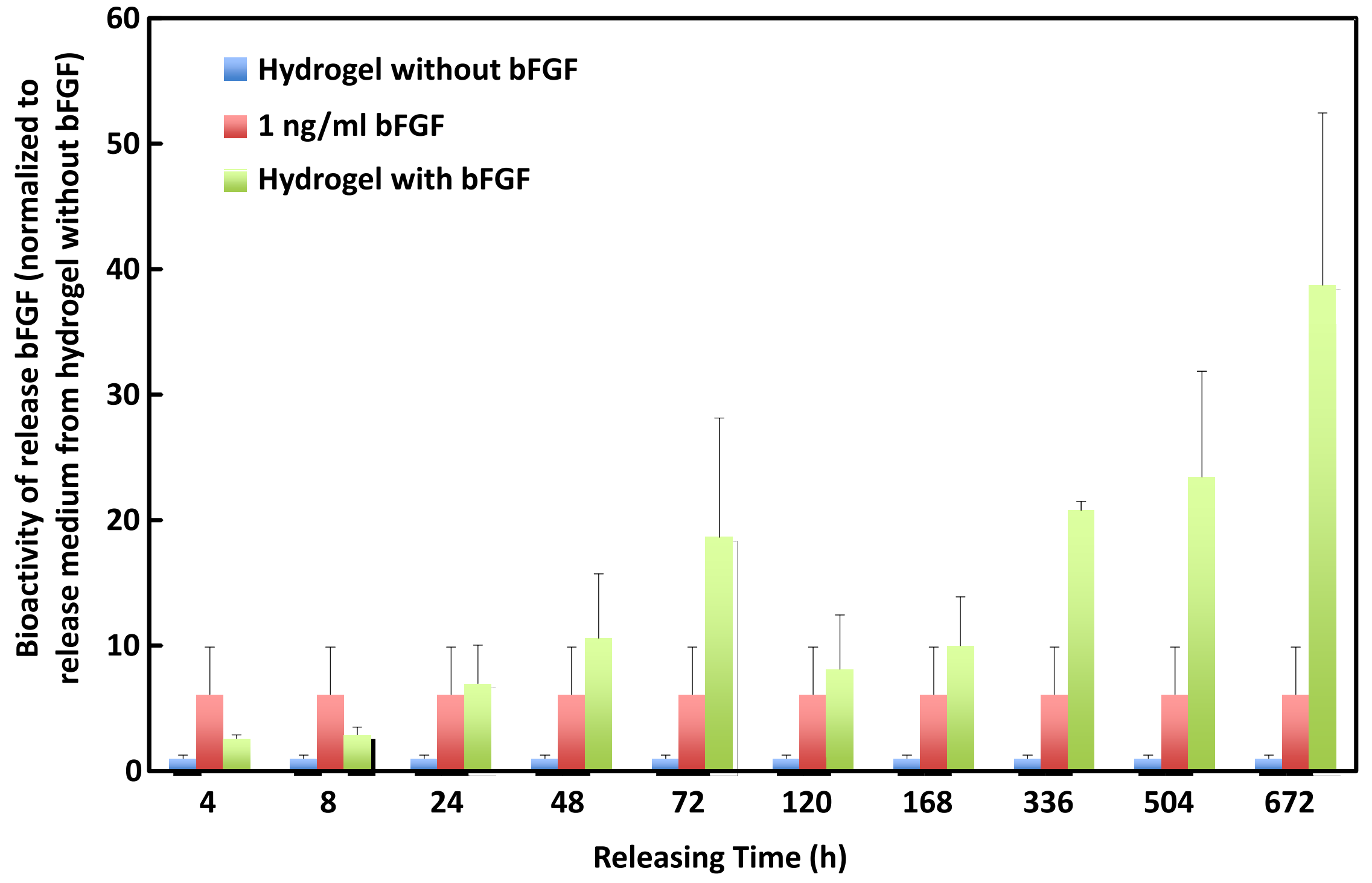

Figure 1.B 


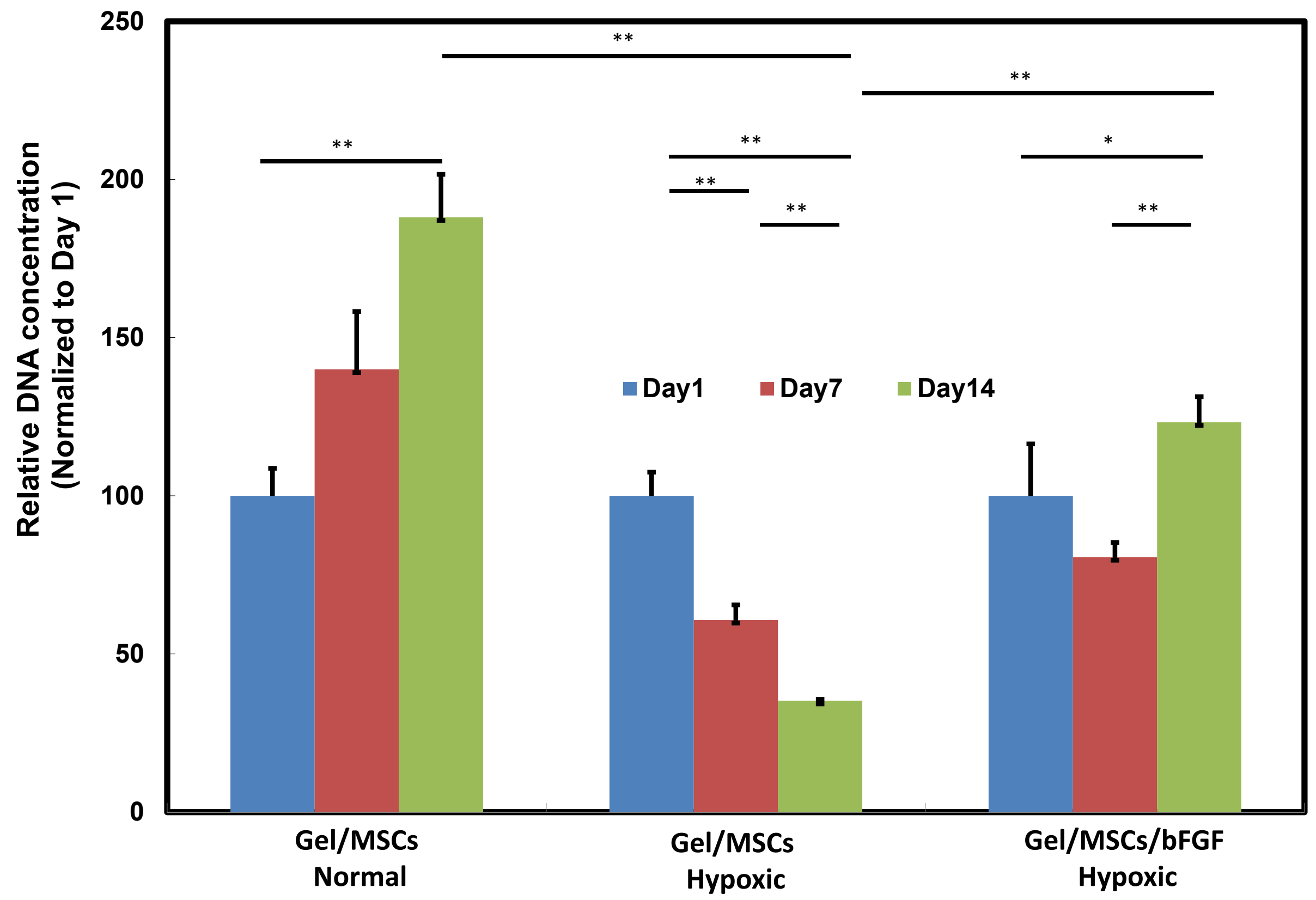

Figure 2.A 


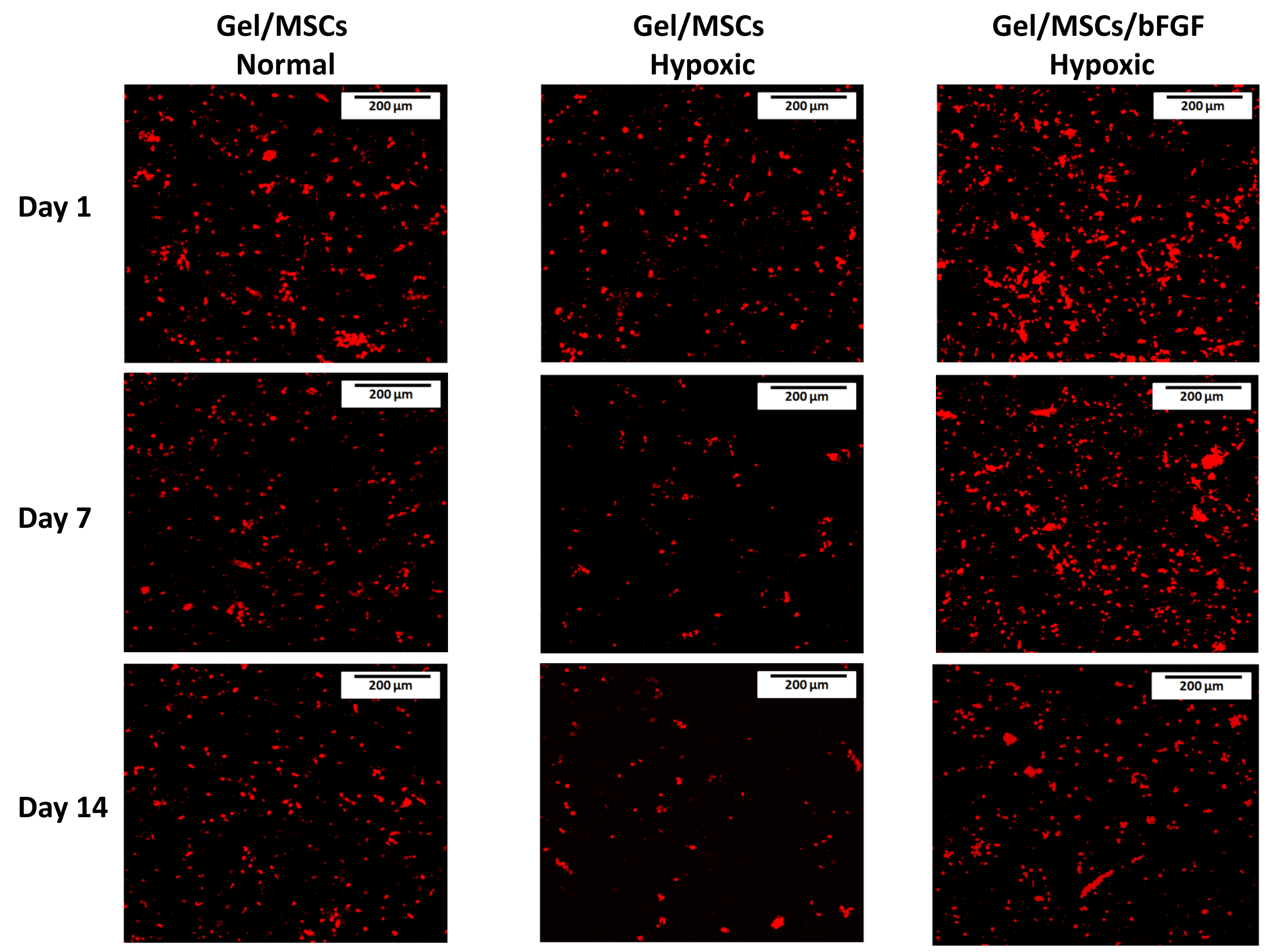

Figure 2.B 


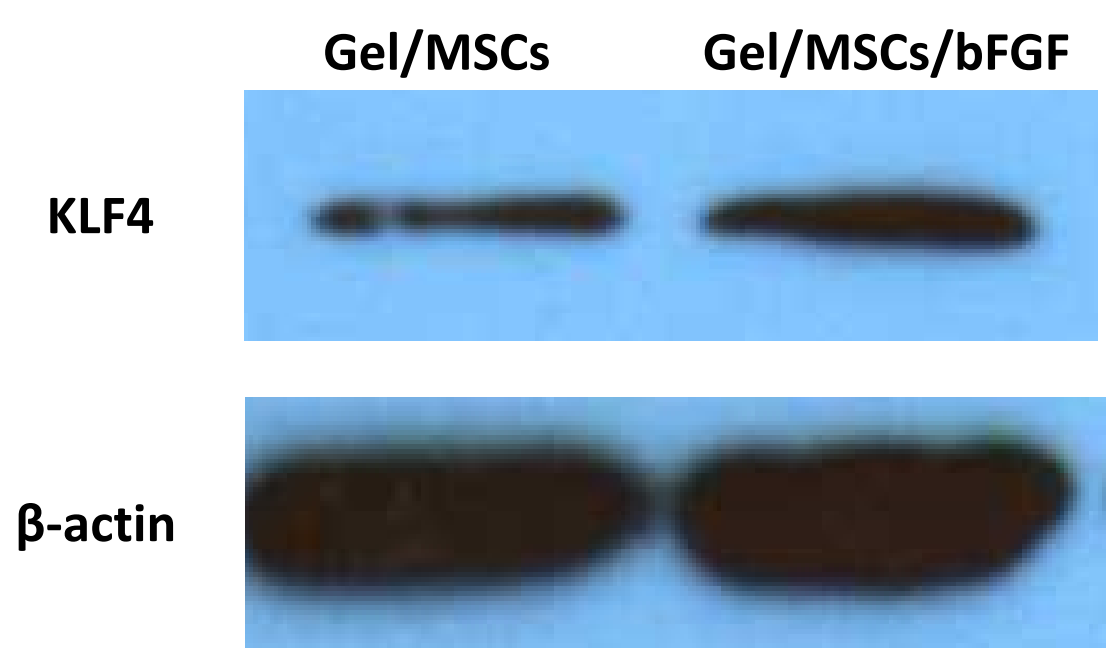

Figure 3 


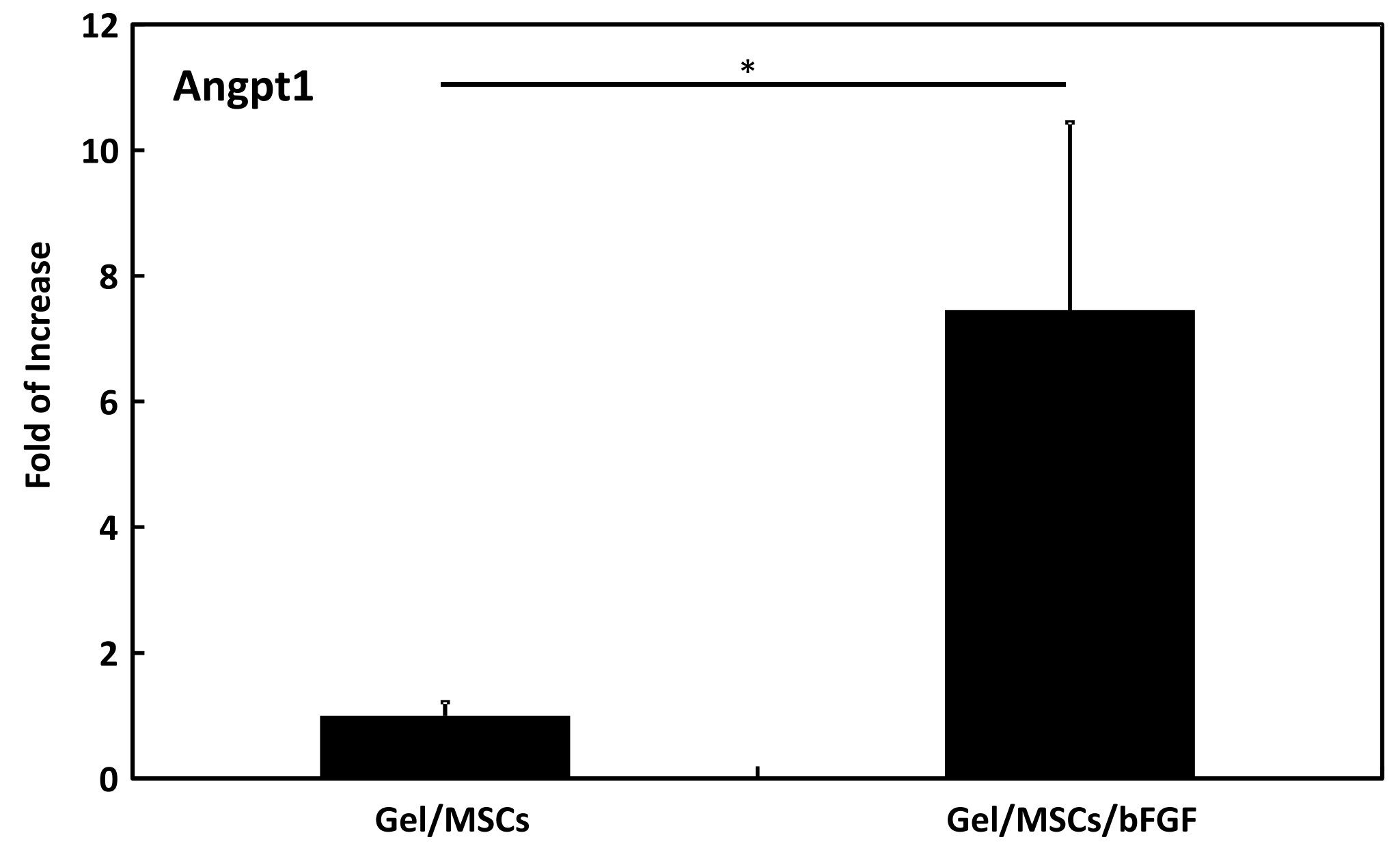

Figure 4 


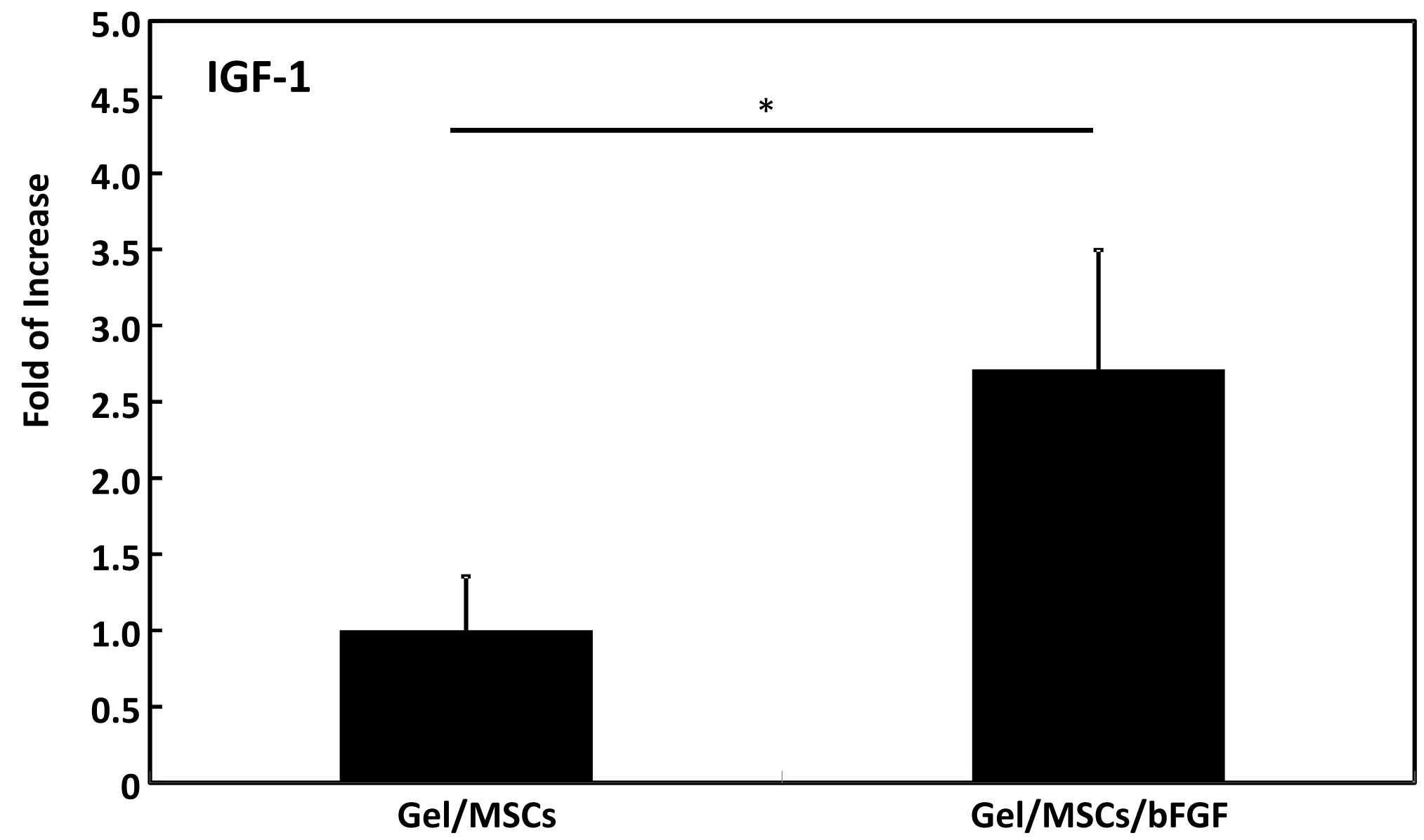

Figure 4 


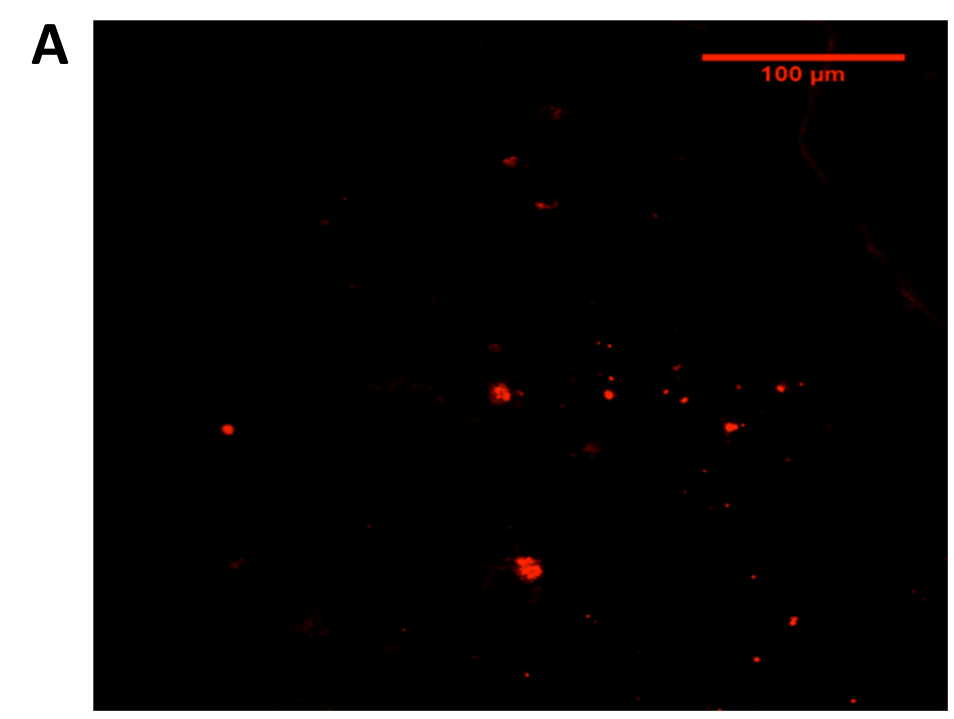

Gel/MSCs

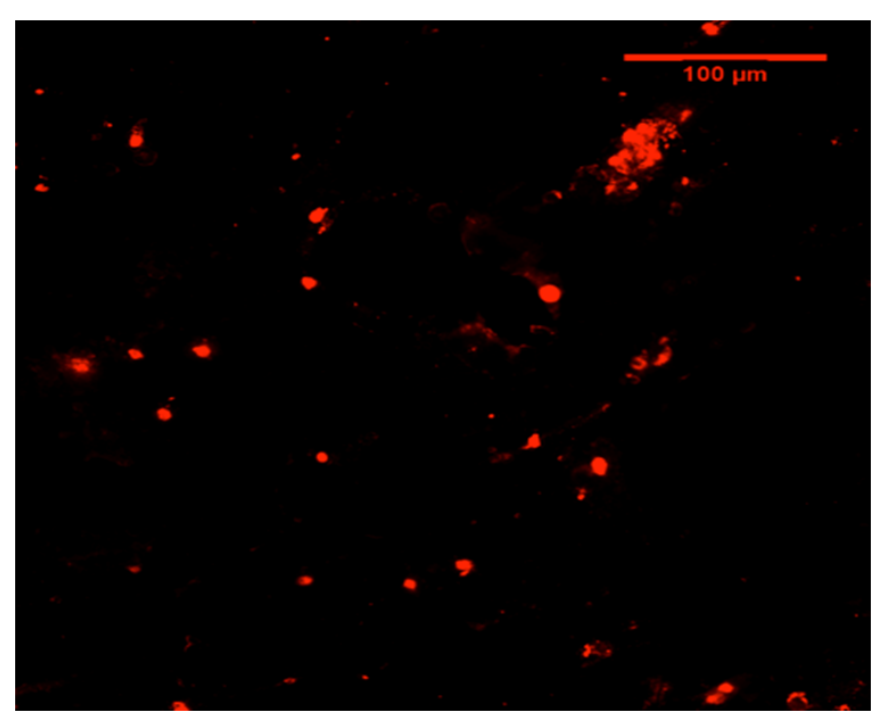

Gel/MSCs/bFGF

Figure 5

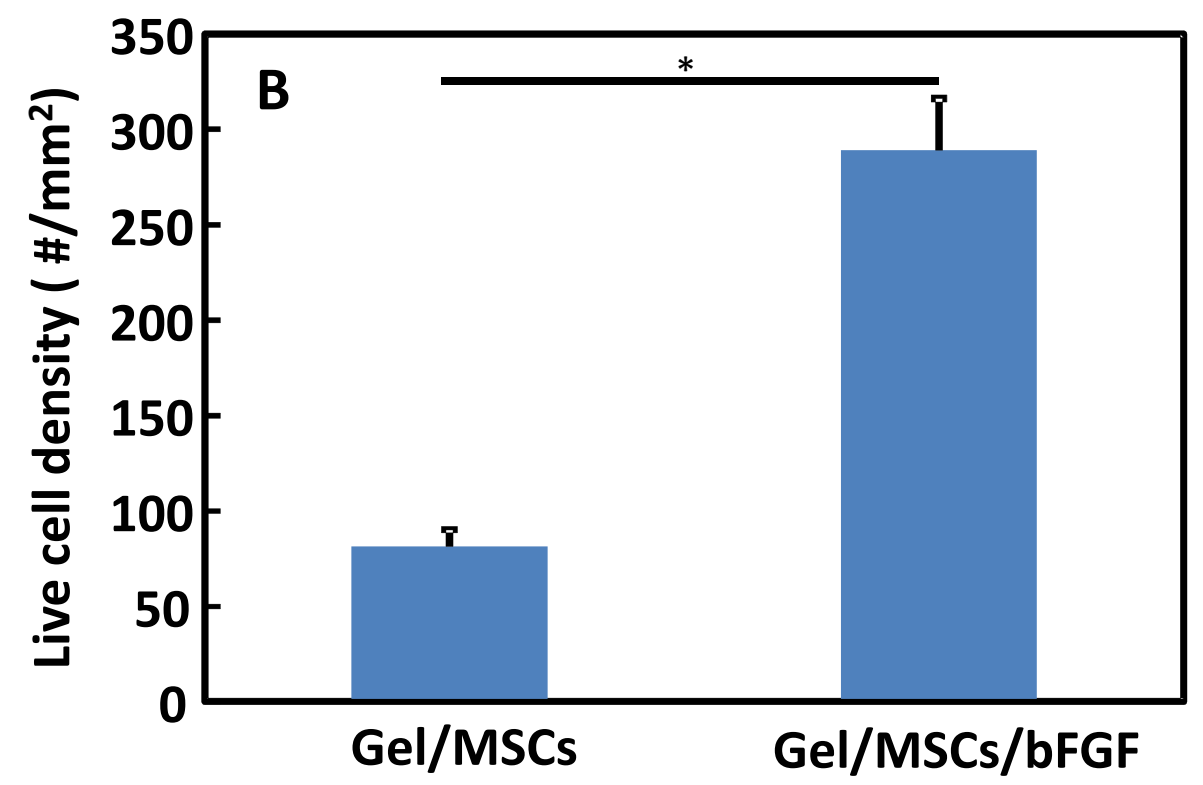




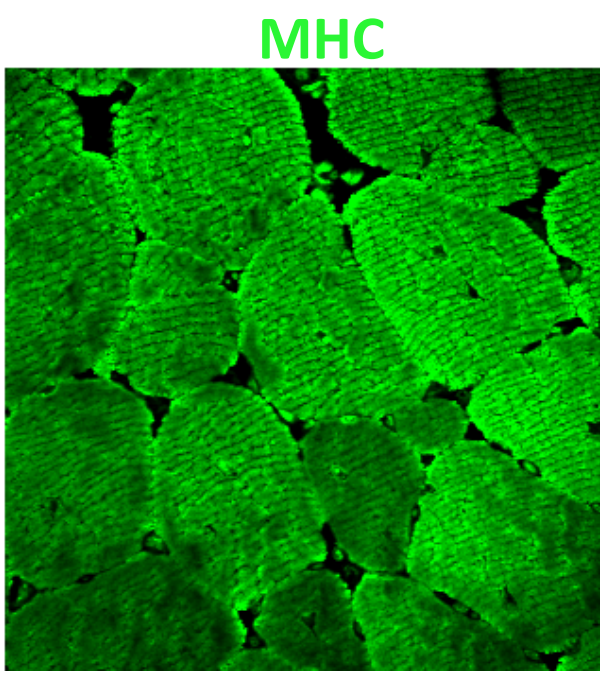

CM-Dil

vWF

Merge

$\uparrow$

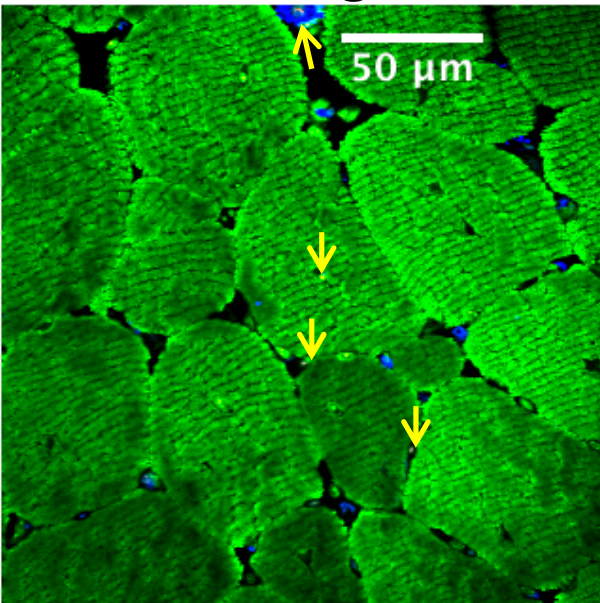

Gel/MSCs

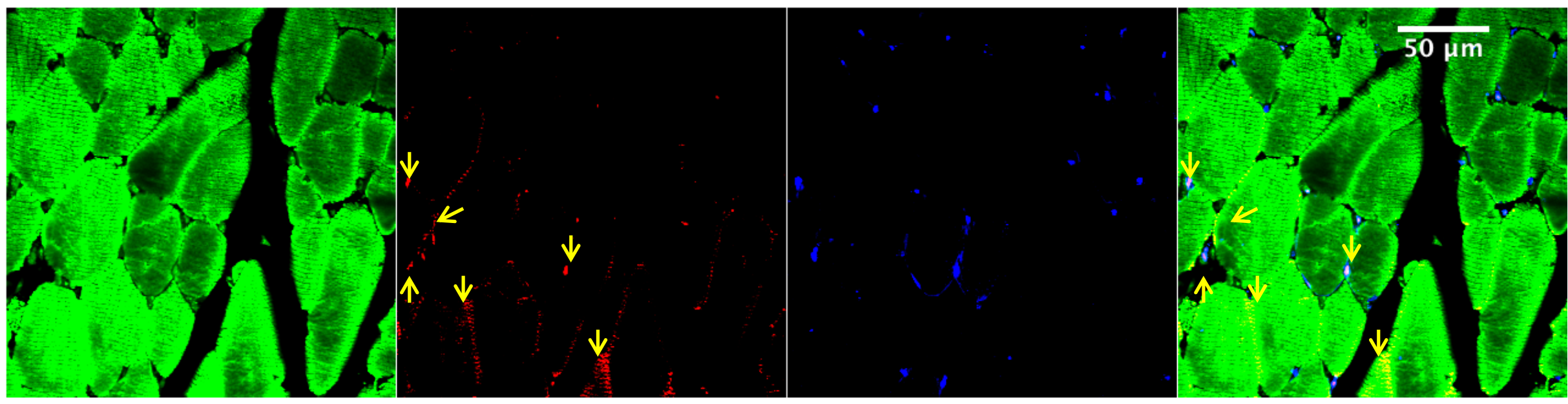

Gel/MSCs/bFGF

Figure 6 

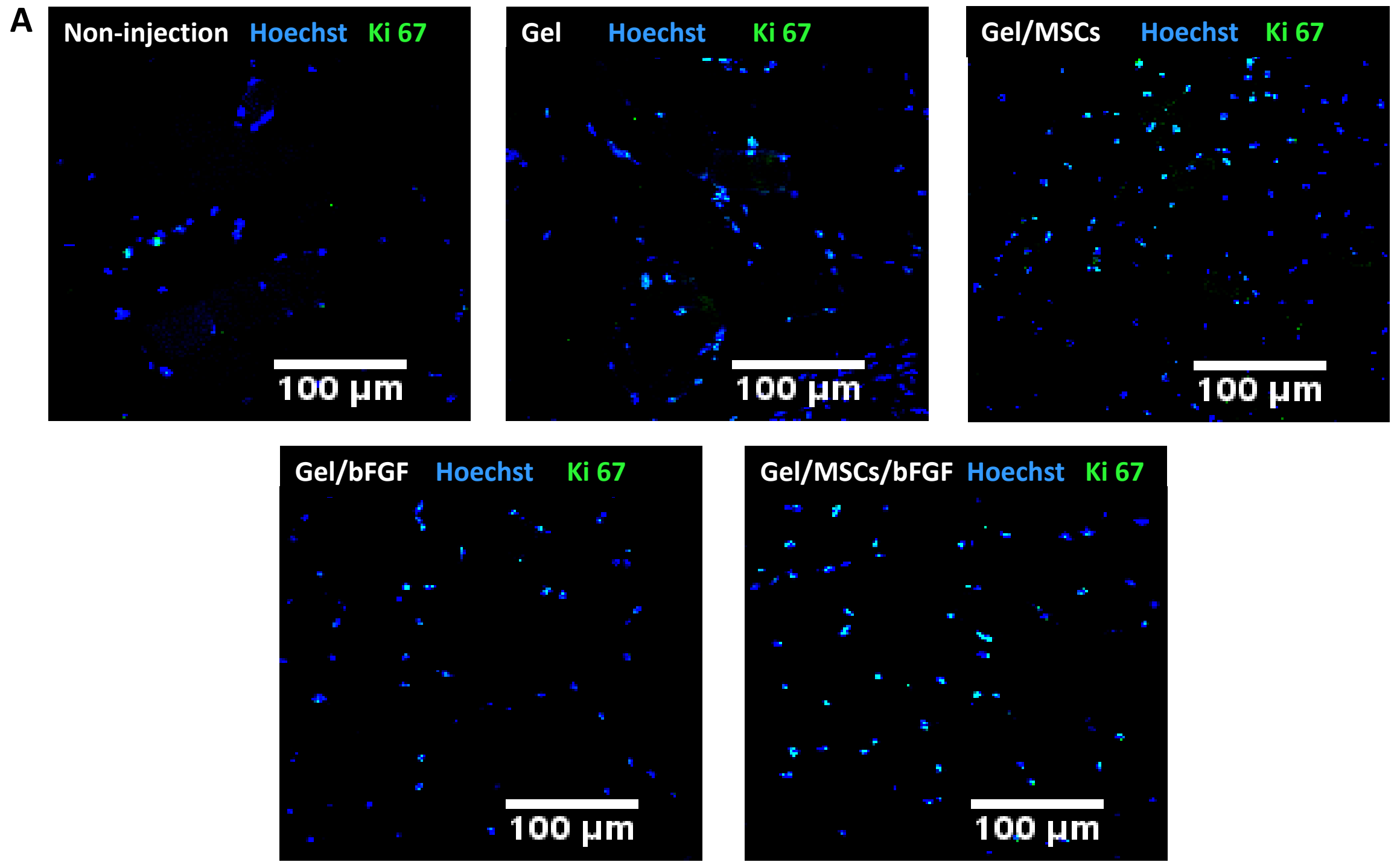

Figure 7.A 


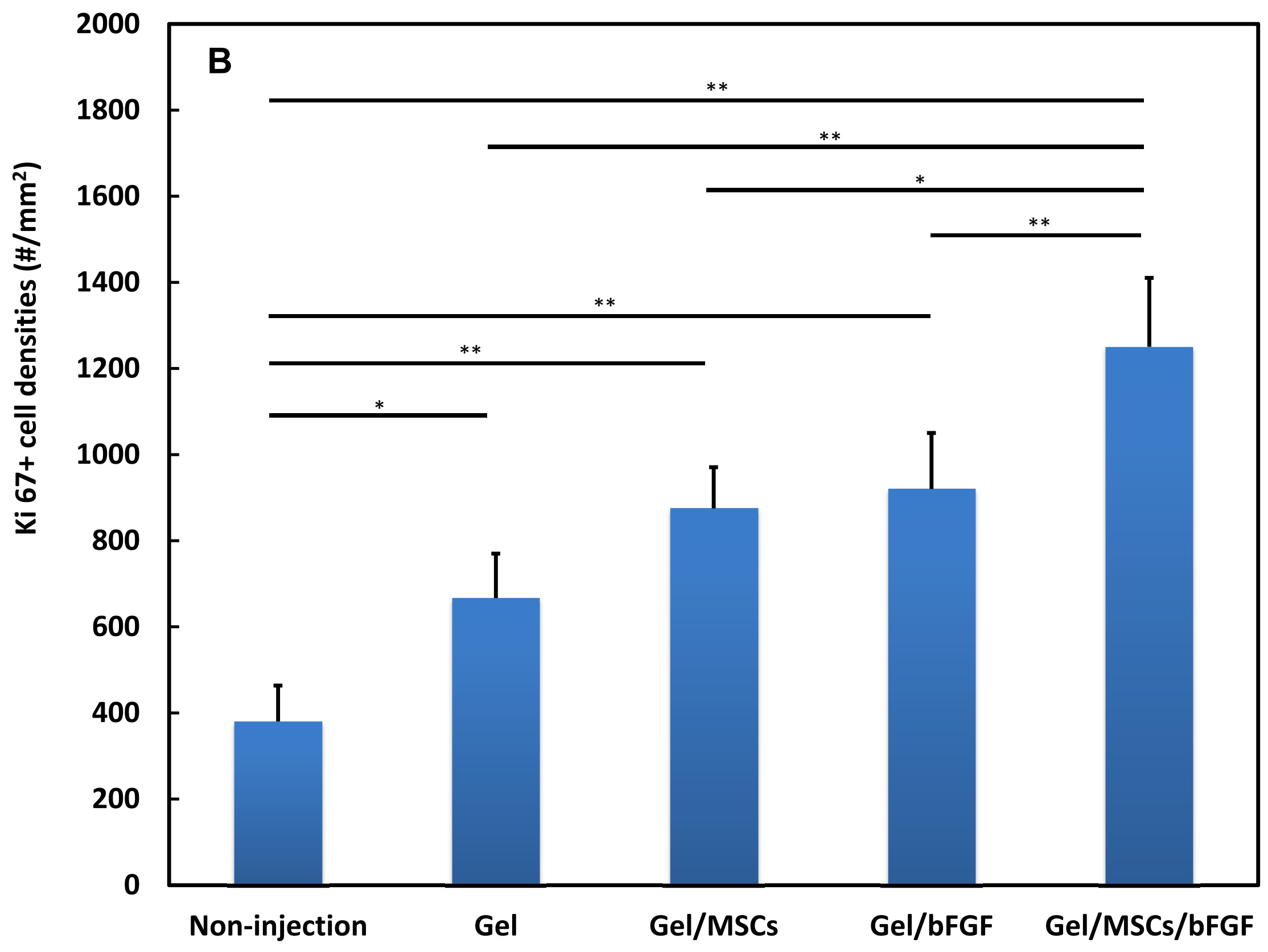

Figure 7.B 

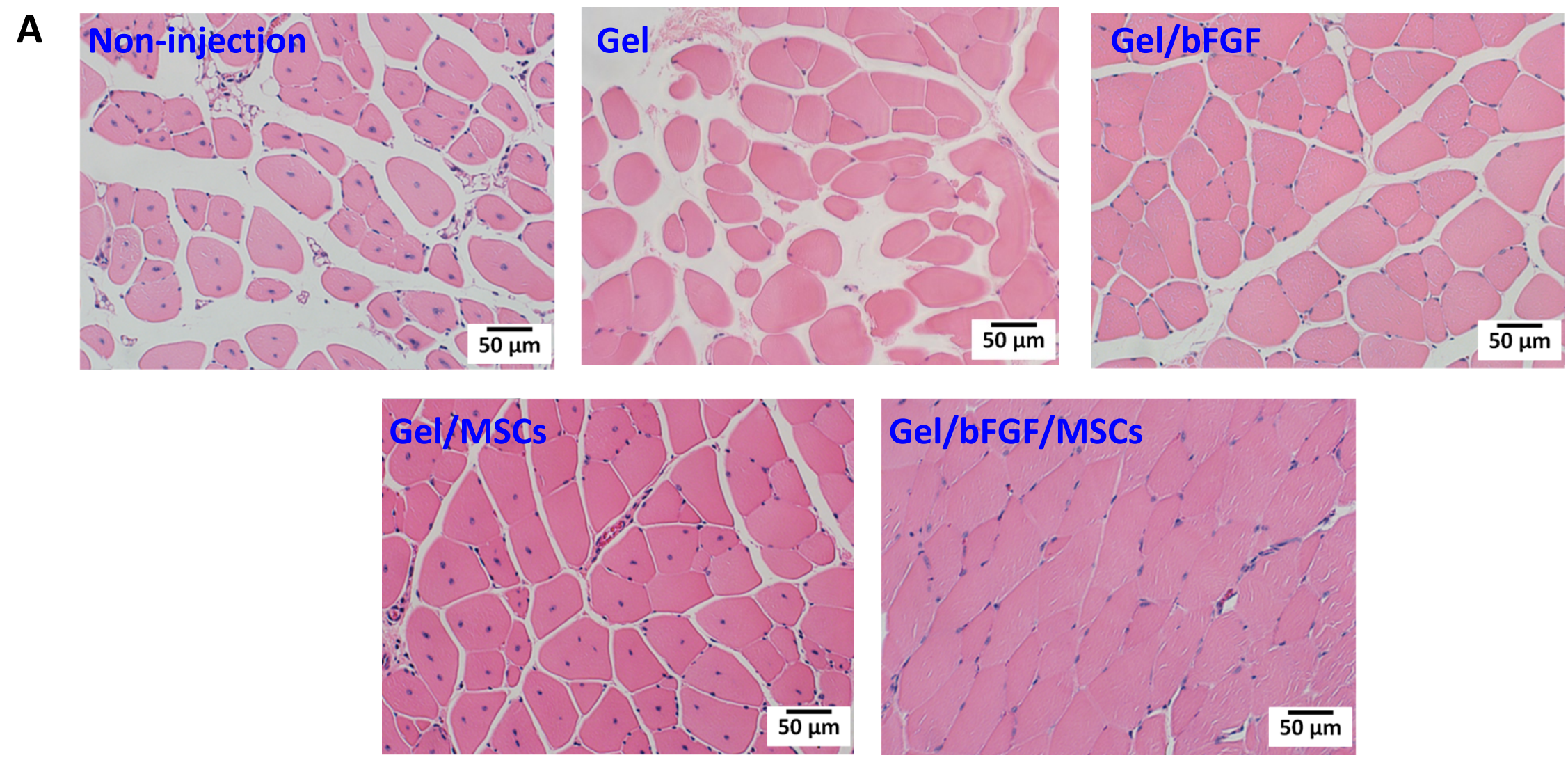

Figure 8.A 


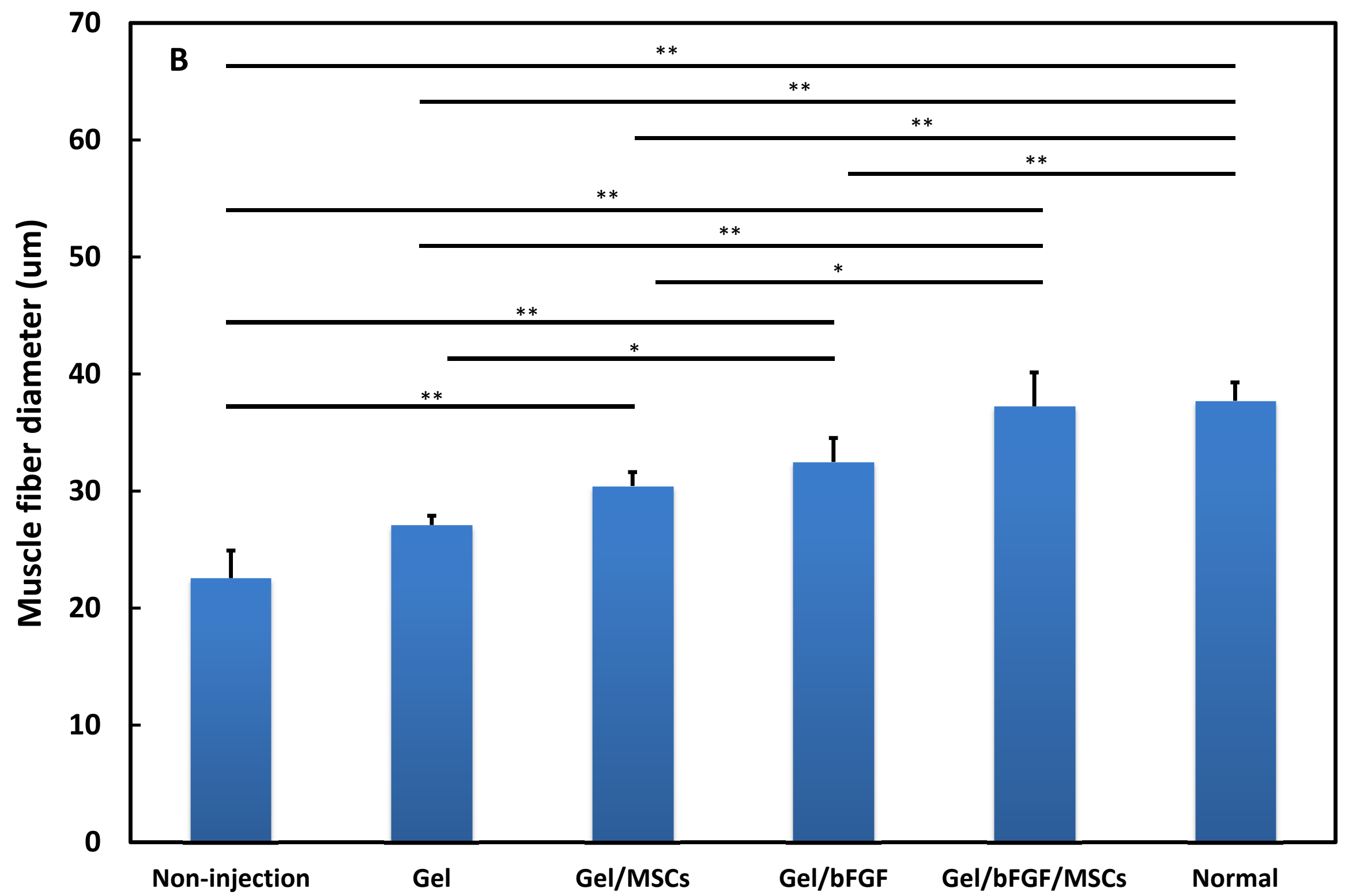

Figure 8.B 

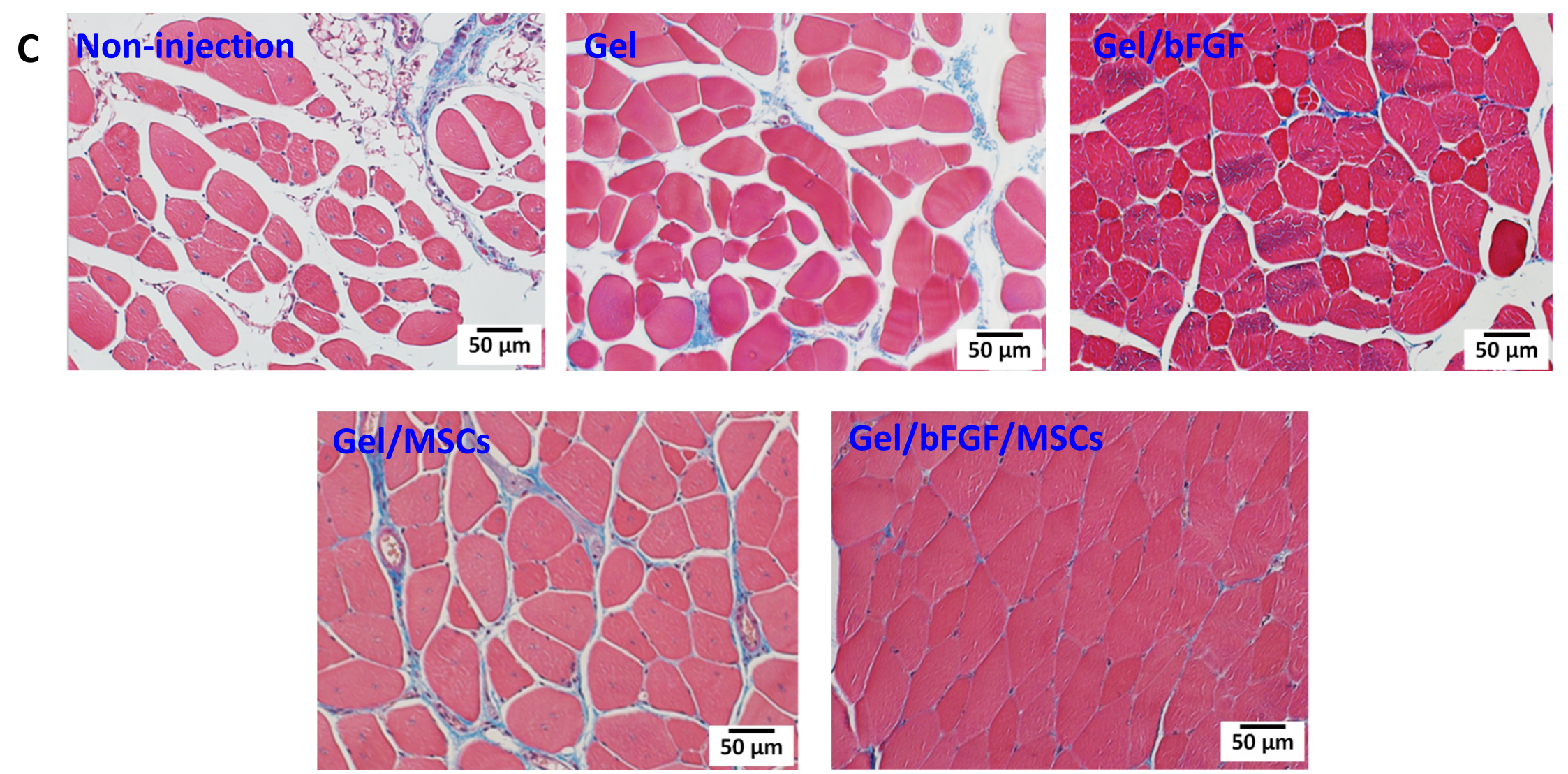

Figure 8.C 


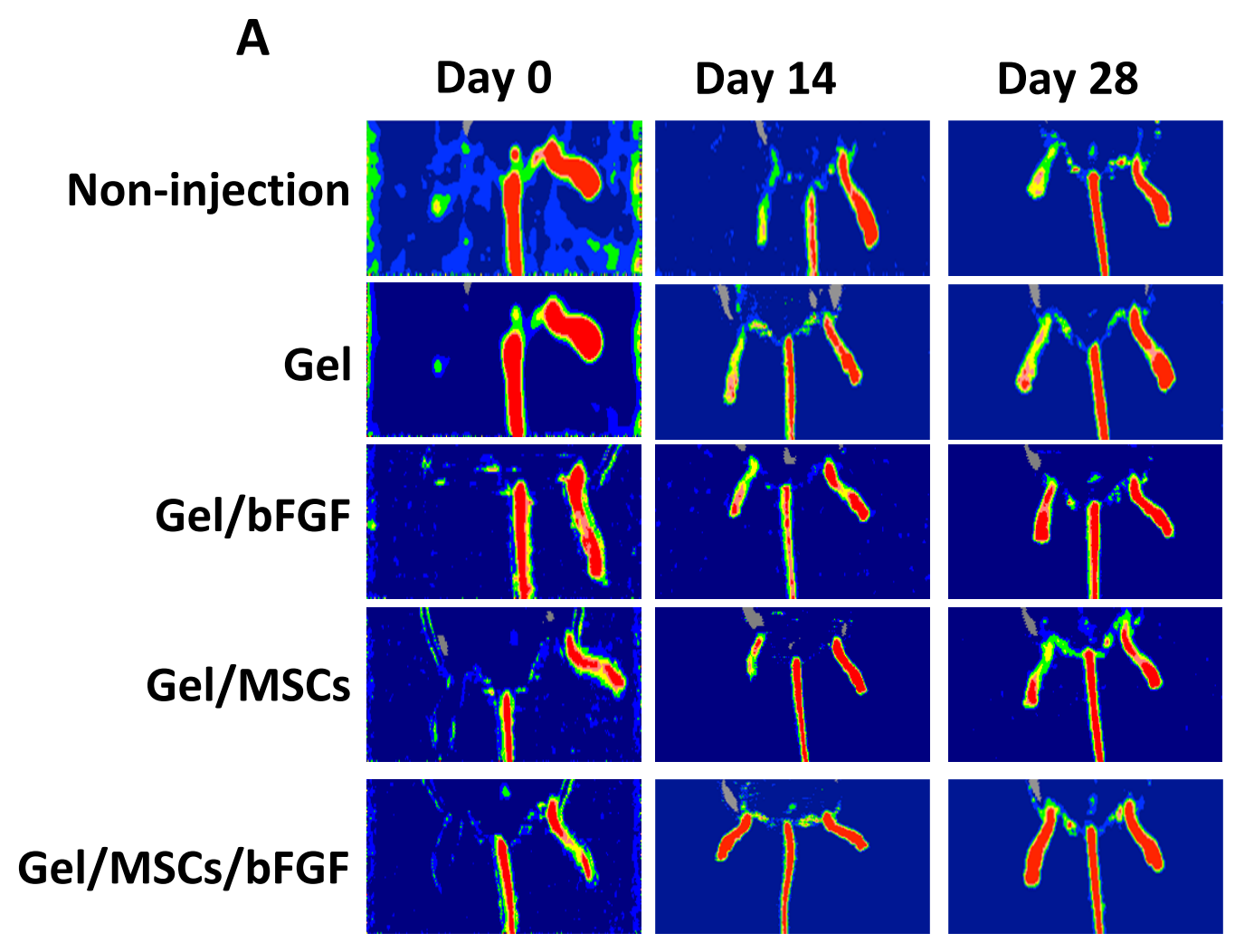

Figure 9.A 


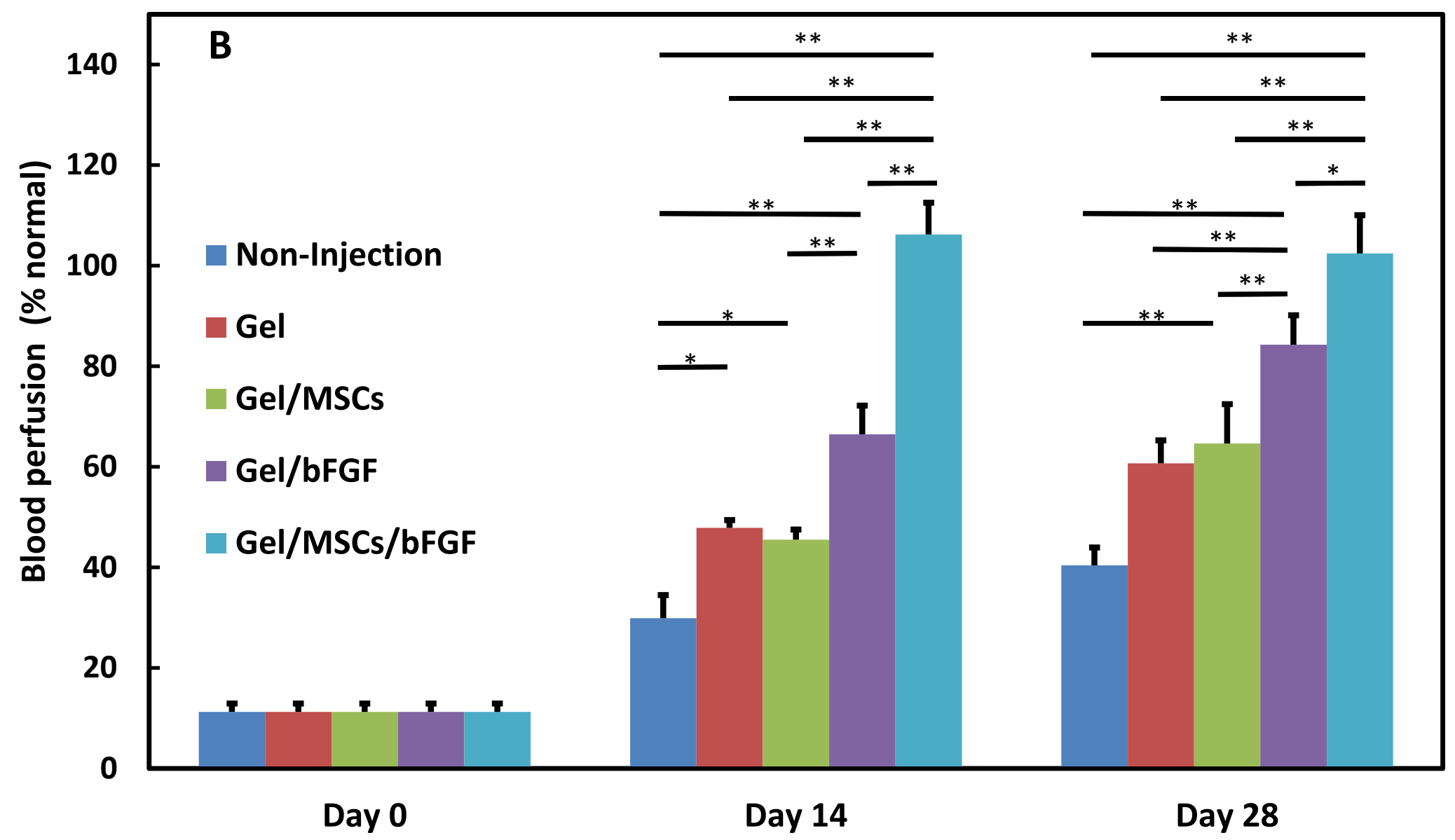

Figure 9.B 

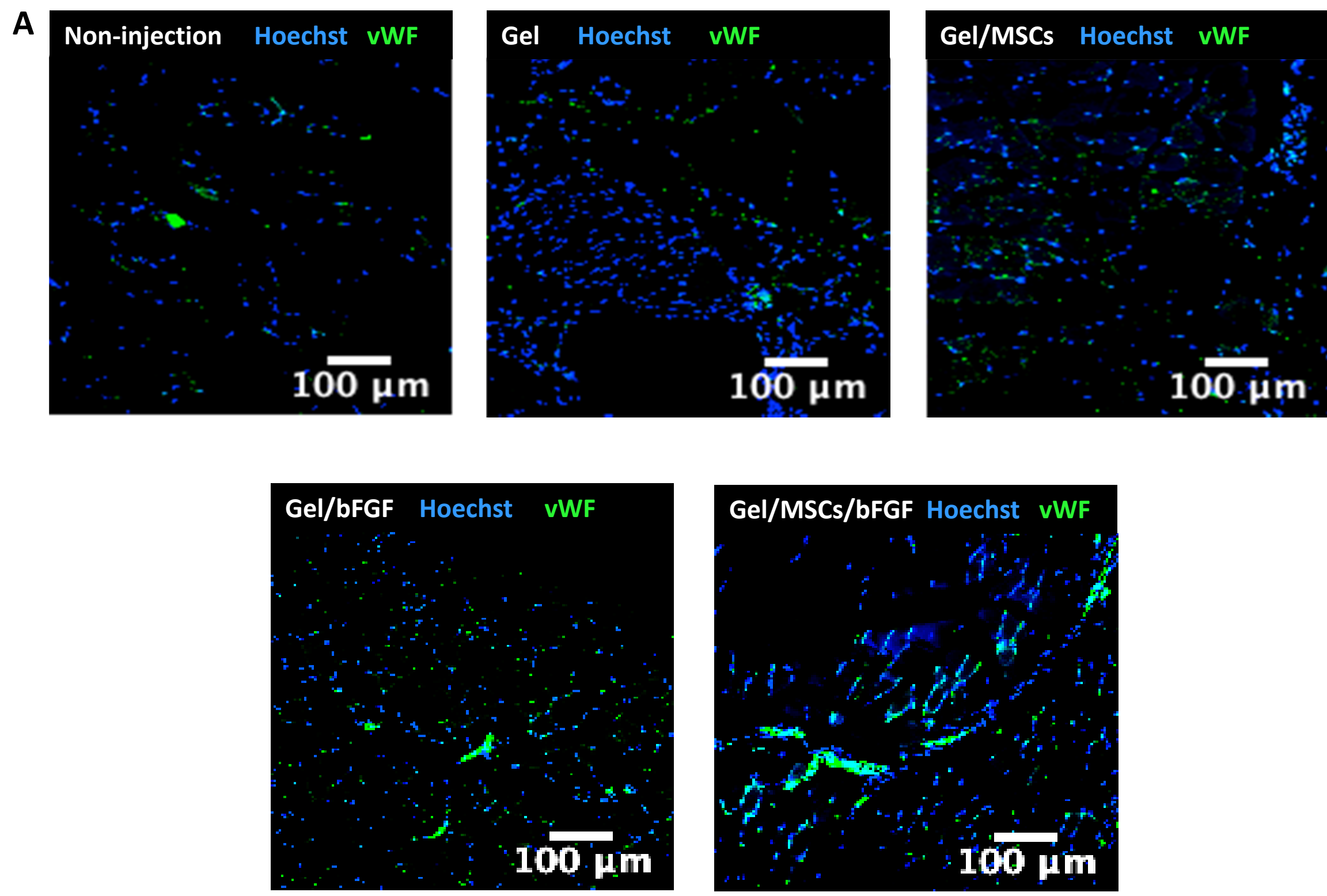

Figure 10.A 


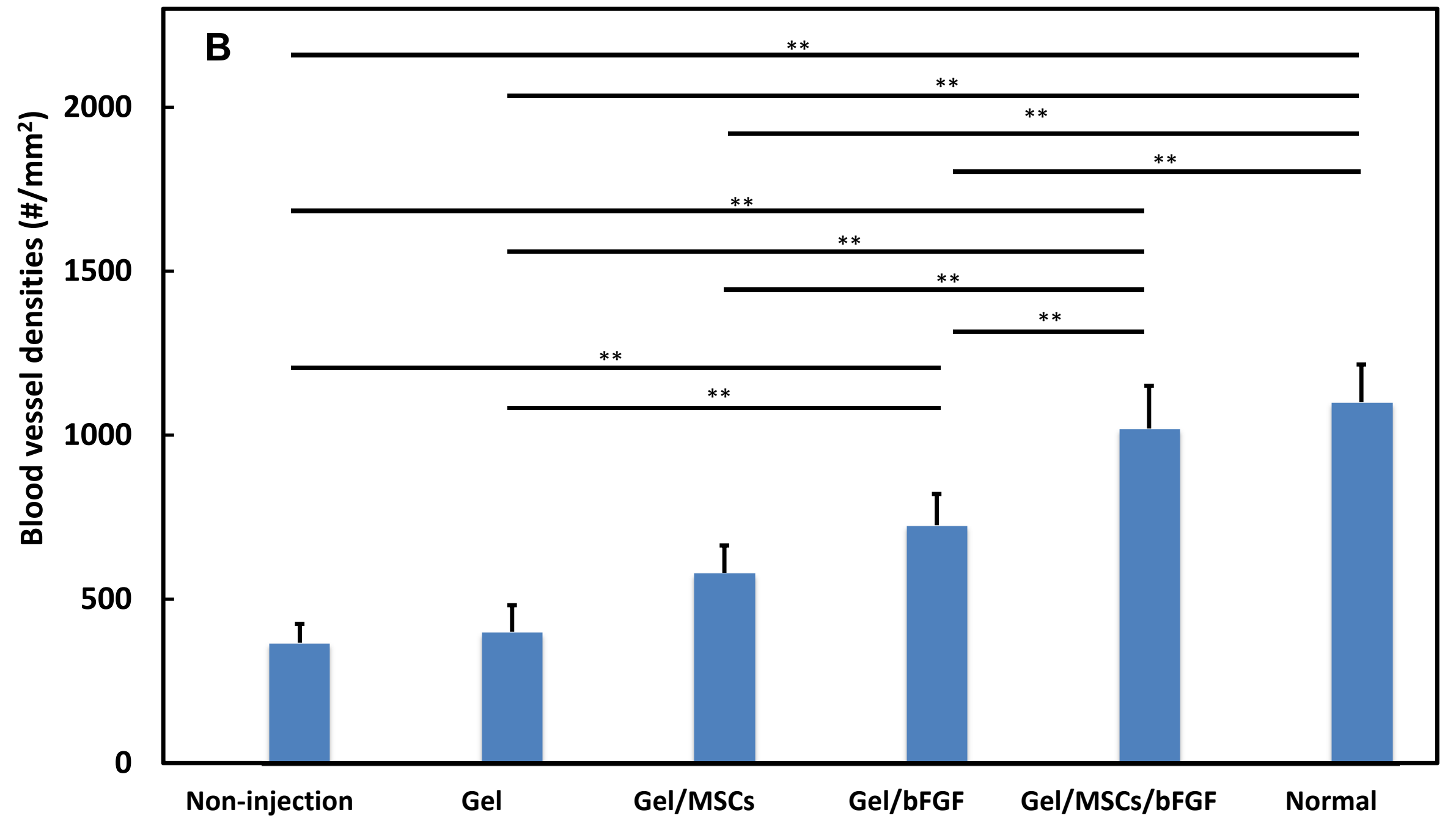

Figure 10.B 